\title{
A microphysics guide to cirrus clouds - Part 1: Cirrus types
}

\author{
Martina Krämer $^{1}$, Christian Rolf ${ }^{1}$, Anna Luebke ${ }^{1, a}$, Armin Afchine ${ }^{1}$, Nicole Spelten ${ }^{1}$, Anja Costa ${ }^{1}$, Jessica Meyer ${ }^{1, b}$, \\ Martin Zöger ${ }^{2}$, Jessica Smith ${ }^{3}$, Robert L. Herman ${ }^{4}$, Bernhard Buchholz ${ }^{5, c}$, Volker Ebert ${ }^{5}$, Darrel Baumgardner ${ }^{6}$, \\ Stephan Borrmann ${ }^{7}$, Marcus Klingebiel ${ }^{7, d}$, and Linnea Avallone ${ }^{8, a}$ \\ ${ }^{1}$ Research Center Jülich, Institute for Energy and Climate Research-7, Jülich, Germany \\ ${ }^{2}$ Deutsches Zentrum für Luft- und Raumfahrt, Flugexperimente - Mess- und Sensortechnik, Wessling, Germany \\ ${ }^{3}$ Harvard University, Harvard John A. Paulson School of Engineering and Applied Sciences, Cambridge, MA, USA \\ ${ }^{4}$ Jet Propulsion Laboratory, California Institute of Technology, Pasadena, CA, USA \\ ${ }^{5}$ Physikalisch-Technische Bundesanstalt, Braunschweig, Germany \\ ${ }^{6}$ Droplet Measurement Technologies, Boulder, CO, USA \\ ${ }^{7}$ Johannes-Gutenberg University and Max-Planck Institute for Chemistry, Mainz, Germany \\ ${ }^{8}$ Division of Atmospheric and Geospace Sciences, National Science Foundation, Arlington, VA, USA \\ ${ }^{a}$ formerly at: University of Colorado, Laboratory for Atmospheric and Space Physics, Boulder, CO, USA \\ bnow at: Bundesanstalt für Arbeitsschutz und Arbeitsmedizin, Unit "Exposure Scenarios", Dortmund, Germany \\ ${ }^{c}$ now at: Princeton University, Department of Civil and Environmental Engineering, USA \\ ${ }^{d}$ now at: Max-Planck-Institute for Meteorology, Hamburg, Germany \\ Correspondence to: Martina Krämer (m.kraemer@fz-juelich.de)
}

Received: 23 October 2015 - Published in Atmos. Chem. Phys. Discuss.: 11 November 2015

Revised: 5 February 2016 - Accepted: 26 February 2016 - Published: 16 March 2016

\begin{abstract}
The microphysical and radiative properties of cirrus clouds continue to be beyond understanding and thus still represent one of the largest uncertainties in the prediction of the Earth's climate (IPCC, 2013). Our study aims to provide a guide to cirrus microphysics, which is compiled from an extensive set of model simulations, covering the broad range of atmospheric conditions for cirrus formation and evolution. The model results are portrayed in the same parameter space as field measurements, i.e., in the Ice Water ContentTemperature (IWC-T) parameter space. We validate this cirrus analysis approach by evaluating cirrus data sets from 17 aircraft campaigns, conducted in the last 15 years, spending about $94 \mathrm{~h}$ in cirrus over Europe, Australia, Brazil as well as South and North America. Altogether, the approach of this study is to track cirrus IWC development with temperature by means of model simulations, compare with observations and then assign, to a certain degree, cirrus microphysics to the observations. Indeed, the field observations show characteristics expected from the simulated Cirrus Guide. For example, high (low) IWCs are found together with high (low) ice crystal concentrations $N_{\text {ice }}$.
\end{abstract}

An important finding from our study is the classification of two types of cirrus with differing formation mechanisms and microphysical properties: the first cirrus type forms directly as ice (in situ origin cirrus) and splits in two subclasses, depending on the prevailing strength of the updraft: in slow updrafts these cirrus are rather thin with lower IWCs, while in fast updrafts thicker cirrus with higher IWCs can form. The second type consists predominantly of thick cirrus originating from mixed phase clouds (i.e., via freezing of liquid droplets - liquid origin cirrus), which are completely glaciated while lifting to the cirrus formation temperature region $(<235 \mathrm{~K})$. In the European field campaigns, slow updraft in situ origin cirrus occur frequently in low- and high-pressure systems, while fast updraft in situ cirrus appear in conjunction with jet streams or gravity waves. Also, liquid origin cirrus mostly related to warm conveyor belts are found. In the US and tropical campaigns, thick liquid origin cirrus which are formed in large convective systems are detected more frequently. 


\section{Introduction}

The appearance of high-altitude cirrus clouds, consisting of pure ice crystals in a cold environment where liquid water no longer exists ${ }^{1}$, is not only intriguing but also a research topic for the past 100 years. The impact of cirrus on climate has been studied since the early 1970s. Cox (1971), for example, questioned whether the presence of cirrus clouds tends to warm or cool the Earth's surface and came to the conclusion that tropical cirrus may have a significant warming tendency while mid-latitude cirrus produce a cooling effect. This is consistent with our understanding today, however, the question of the net global effect of cirrus clouds is still not answered definitively. The latest IPCC report (Boucher et al., 2013) states that together, clouds and aerosols continue to contribute the largest uncertainty to estimates and interpretations of the Earth's changing energy budget and that particularly the fundamental details of the microphysical processes of ice clouds are still poorly understood.

A major reason for this continuing uncertainty is the difficulty of measuring the respective key parameters with the required accuracy on fast-flying jet aircraft at high altitudes, as well as from ground-based and space-borne remote-sensing platforms. Another problem is that aircraft measurements cannot capture the evolution of the cirrus cloud properties with time, but provide only snapshots of cirrus properties at the thermodynamic conditions encountered. In most cases, the measurements are shown along the flight tracks where they were obtained or as a function of altitude or temperature. Because of this sampling strategy, it is difficult to study cirrus processes from formation to dissipation based on in situ observations. Instead, statistically based approaches appear more promising.

The most common parameters that are measured in cirrus clouds - besides the meteorological variables - are ice water content (IWC), ice crystal number $\left(N_{\text {ice }}\right)$, crystal size and shape as well as relative humidity (with respect to ice, $\mathrm{RH}_{\text {ice }}$ ). Sometimes the number and properties of ice nucleating particles (IN) and vertical velocity are also measured. Unfortunately, the measurements of ice crystal number and size as well as $\mathrm{RH}_{\text {ice }}$ have suffered from instrument issues over the last decades (see e.g. Peter et al., 2006; McFarquhar et al., 2011; Korolev et al., 2011, 2013; Krämer et al., 2013) so that interpretations of earlier observations should be made cautiously. Moreover, it is difficult to draw conclusions about the history of ice nucleation and the evolution of microphysical properties from these observations. Nevertheless, there are numerous aircraft and satellite-based observations, as well as modeling studies contributing to the field of cirrus research (e.g. Heymsfield and Iaquinta, 2000; McFarquhar et al., 2000; Sassen and Benson, 2001; Com-

\footnotetext{
${ }^{1}$ This is below about $235 \mathrm{~K}\left(-38^{\circ} \mathrm{C}\right)$; large ice crystals falling out of cirrus clouds can be observed at higher temperatures as "fall streaks".
}

stock et al., 2002; Heymsfield et al., 2002a, b; Kärcher and Lohmann, 2002, 2003; DeMott et al., 2003; Cziczo et al., 2004; Archuleta et al., 2005; Möhler et al., 2006; Sassen et al., 2008; Gettelman et al., 2010; Hoose and Möhler, 2012; Cziczo et al., 2013) ${ }^{2}$.

To help understand the appearance, properties and microphysical processes of cirrus clouds, our study aims to provide a guide to cirrus microphysics in a parameter space easily accessible by field measurements, i.e., in the IWCTemperature (IWC-T) portrayal. The reason for this choice is that bulk IWC is a very robust parameter under different aspects: IWC is not as sensitive to atmospheric variations as ice crystal numbers. In addition, the measurement of bulk IWC is less complicated than ice crystal measurements and, finally, this study expands our previous work based on IWC observations (Schiller et al., 2008; Krämer et al., 2009; Luebke et al., 2013; note also the large IWC database presented by Heymsfield et al., 2013 and the analysis of cirrus observations during the field campaign SPARTICUS by Muhlbauer et al., 2014, see Sect. 5.5). Our new approach is to track cirrus IWC development with temperature by means of model simulations, compare with observations and then assign cirrus microphysics and formation mechanisms to the observations.

The first pillar of this work is the comprehensive measurements from the multiple field campaigns we have conducted in the last 15 years with reliable instrumentation where instrument issues are minimized (see Sect. 2). Second, a "Cirrus Guide" is compiled from an extensive set of model simulations (see Sects. 3 and 4), covering the broad range of atmospheric conditions for cirrus formation and evolution. The model results are then portrayed in the IWC-T parameter space and validated by evaluating the data sets from the field campaigns. From the representation of simulated cirrus, we can then assign, to a certain degree, cirrus microphysics, history and the formation mechanism to specific combinations of IWC, $N_{\text {ice }}$ and $\mathrm{RH}_{\text {ice }}$ inside and outside of cirrus as a function of temperature.

In Part 1 of the study, the field measurements as well as the Cirrus Guide simulations are described and the results with respect to cirrus microphysics and possible history are presented (see Sect. 5). Part 2 contains the assignment of the cirrus formation mechanisms to the observations.

\section{Cirrus observations}

Cirrus clouds were observed during 17 field campaigns performed between 1999 and 2014 over Europe, Africa, Seychelles, Brazil, Australia, USA and Costa Rica. A map of all

\footnotetext{
${ }^{2}$ Out of the nearly thousand cirrus studies since 2000 , we provide a list here - created using the Web of Science - containing the 10 most cited and the highly cited studies and also 5 most or highly cited ice nucleation and global modeling studies; references contained already in this paper are not considered.
} 


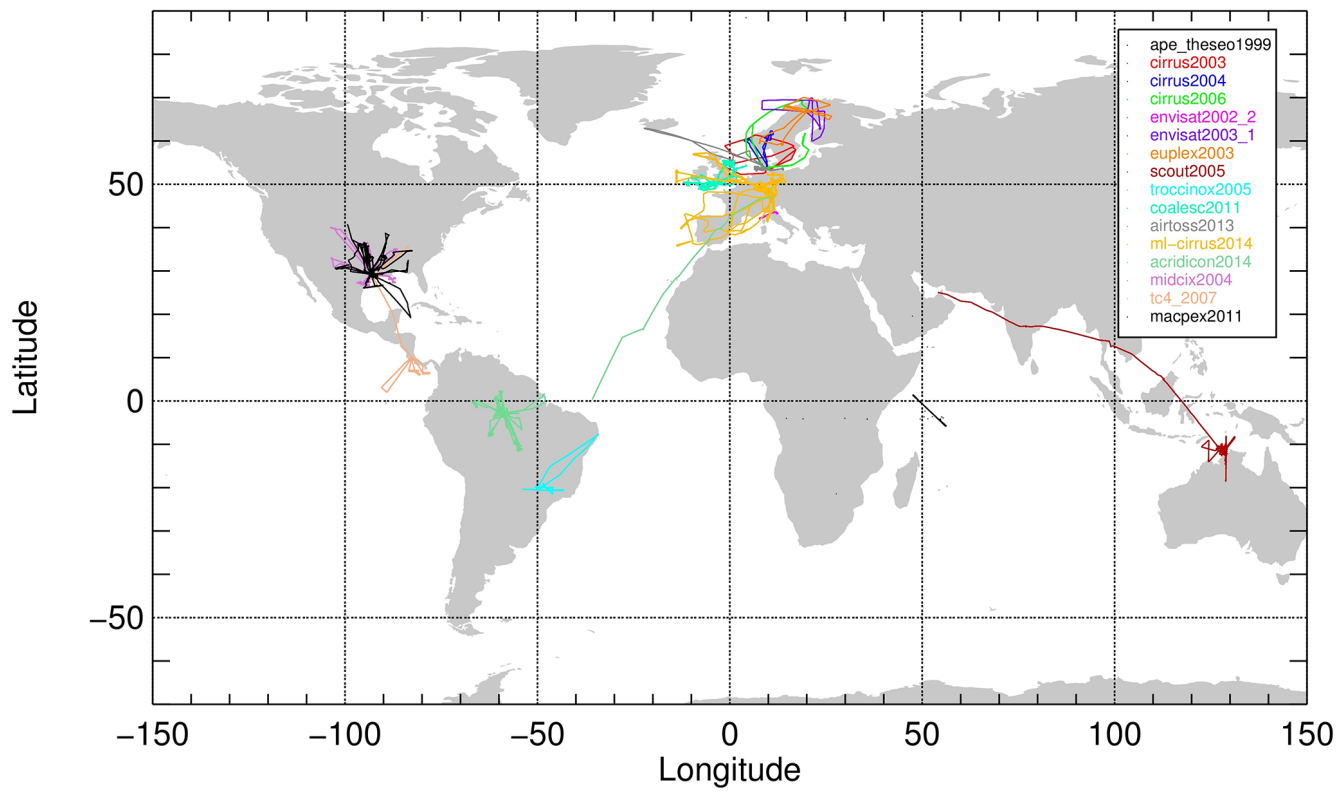

Figure 1. Aircraft flight paths during the campaigns listed above. Total number of flights: 104, total time of IWC measurements: $93.6 \mathrm{~h}$.

Table 1. Overview of campaigns and instruments. IWC: ice water content, $\mathrm{RH}_{\mathrm{ice}}$ : relative humidity over ice, $N_{\text {ice }}$ : ice crystal number concentration.

\begin{tabular}{|c|c|c|c|c|}
\hline Aircraft & Locations & IWC & $\mathrm{RH}_{\text {ice }}$ & $N_{\text {ice }}$ \\
\hline Geophysica & Seychelles $^{1}$, Europe $^{2}$, Brazil $^{3}$, Australia $^{4}$, Africa $^{5}$ & FISH $^{\mathrm{a}}$ & FLASH $^{\mathrm{c}}$ & FSSP-100i \\
\hline Learjet & Europe ${ }^{6}$ & $\mathrm{FISH}^{\mathrm{a}}$ & OJSTER $^{\mathrm{d}}$, SEAL $^{\mathrm{e}}$ & FSSP- $300^{j}$ \\
\hline WB-57 & $\mathrm{USA}^{7}$, Costa Rica $^{8}$ & $\mathrm{CLH}^{\mathrm{b}}$ & $\mathrm{HWV}^{\mathrm{f}}, \mathrm{JLH}^{\mathrm{g}}$ & CAPS $^{\mathrm{k}}, 2-\mathrm{DS}^{1}$ \\
\hline BAe-146 & $\mathrm{UK}^{9}$ & NIXE-CAPS $^{\mathrm{m}}$ & - & NIXE-CAPS $^{m}$ \\
\hline HALO & Europe $^{10}$, Brazil $^{11}$ & NIXE-CAPS ${ }^{\mathrm{m}}$ & SHARC $^{\mathrm{h}}$ & NIXE-CAPS ${ }^{\mathrm{m}}$ \\
\hline
\end{tabular}

The campaigns under 1-6 are described by Schiller et al. (2008); Krämer et al. (2009) and Finger et al. (2015), 7-8 by Luebke et al. (2013); Jensen et al. (2013b), 9 Jones et al. (2012), 10 Voigt (2016), 11 Wendisch et al. (2016). ${ }^{1}$ APE-THESEO 1999. ${ }^{2}$ ENVISAT 2002, EUPLEX 2003, ENVISAT 2003. ${ }^{3}$ TROCCINOX 2005. ${ }^{4}$ SCOUT-O 3 2005. ${ }^{5}$ AMMA 2006. ${ }^{6}$ CIRRUS 2003, CIRRUS 2004, CIRRUS 2006, AIRTOSS-ICE 2013. ${ }^{7}$ MidCix 2004, MACPEX $2011 .{ }^{8}$ TC-4 2007. ${ }^{9}$ COALESC 2011. ${ }^{10}$ ML-CIRRUS 2014. ${ }^{11}$ ACRIDICON-CHUVA 2014. ${ }^{\text {a }}$ Lyman- $\alpha$ fluorescence hygrometer (Schiller et al., 2008; Krämer et al., 2009; Meyer et al., 2015). ${ }^{b}$ Tunable diode laser hygrometer (Luebke et al., 2013). ${ }^{\mathrm{c}}$ Lyman- $\alpha$ fluorescence hygrometer (Krämer et al., 2009). ${ }^{\mathrm{d}}$ Tunable diode laser hygrometer (Krämer et al., 2009). ${ }^{\mathrm{e}}$ Tunable diode laser hygrometer (Buchholz et al., 2013). ${ }^{\mathrm{f}}$ Lyman- $\alpha$ fluorescence hygrometer (Rollins et al., 2014). ${ }^{\mathrm{g}}$ Tunable diode laser hygrometer (May, 1998). ${ }^{\mathrm{h}}$ Tunable diode laser hygrometer (Meyer et al., 2015). ${ }^{\mathrm{i}}$ Light scattering cloud probe (Krämer et al., 2009). ${ }^{\mathrm{j}}$ Light scattering cloud probe (Krämer et al., 2009). ${ }^{\mathrm{k}}$ Light scattering and optical imaging cloud probe (Baumgardner et al., 2001). ${ }^{1}$ optical imaging cloud probe (Lawson et al., 2006). ${ }^{\mathrm{m}}$ Light scattering and optical imaging cloud probe (Meyer, 2012; Luebke et al., 2015).

104 flights is shown in Fig. 1. The total time spent in cirrus clouds sums up to about $94 \mathrm{~h}$. A summary of the campaigns, location, aircraft and the instrumentation on board the different aircraft is given in Table 1 and in the following sections. A variety of established instruments are used here, which are already well described in the literature. For brevity, here we give only that information necessary for this study and respective references for each instrument.

\subsection{Ice water content and humidity measurements}

The ice water content (IWC) is derived during most campaigns from the measurements of $\mathrm{H}_{2} \mathrm{O}_{\text {tot }}$, which is the amount of total water (gas phase + evaporated ice crystals), and $\mathrm{H}_{2} \mathrm{O}_{\text {gas }}$, the gas phase water amount. IWC is then calcu- lated by using the following equation:

IWC $=\left(\mathrm{H}_{2} \mathrm{O}_{\text {tot }}-\mathrm{H}_{2} \mathrm{O}_{\text {gas }}\right) / E$,

where $E$ is the enhanced volume out of which the ice crystals are sampled in comparison to the sampling volume of the gas phase. For more details see Schiller et al. (2008) and Luebke et al. (2013). $\mathrm{H}_{2} \mathrm{O}_{\text {tot }}$ was measured by the total water instruments FISH and CLH (Table 1a and b), $\mathrm{H}_{2} \mathrm{O}_{\text {gas }}$ with the gas phase water instruments FLASH, OJSTER, HWV, JLH, SEAL and SHARC (Table 1c-h). For details about the instruments see the respective references in the table.

Since no total water measurements were available, IWC for COALESC, ML-CIRRUS and ACRIDICON-CHUVA is derived by integrating the ice crystal size distributions from 
NIXE-CAPS (see next section) using the mass-dimension $(m-D)$ relation (see Luebke et al., 2015, modified $m-D$ relation of Mitchell et al., 2010):

$m=a \times D^{b}$

with

$$
\begin{array}{lll}
a=0.001902, \quad b=1.802 & \text { for } & D>240 \mu \mathrm{m} \\
a=0.058000, \quad b=2.700 & \text { for } & D=10-240 \mu \mathrm{m} \\
\text { ice crystals are spheres } & \text { for } & D<10 \mu \mathrm{m} .
\end{array}
$$

In a recent study, Erfani and Mitchell (2015) developed new, observation-based $m-D$ relations. These new relations confirm Mitchell et al. (2010) and show that for the cirrus cloud temperature range $T<-38{ }^{\circ} \mathrm{C}$ the $m-D$ relations have nearly no dependence on temperature or cirrus type, thus demonstrating the robustness of the connection between cirrus ice crystal size and mass.

The relative humidity with respect to ice $\left(\mathrm{RH}_{\text {ice }}\right.$; shown in Part 2 of the study) is also derived from $\mathrm{H}_{2} \mathrm{O}_{\text {gas }}$ using

$\mathrm{RH}_{\text {ice }}=100 \times \frac{\mathrm{H}_{2} \mathrm{O}_{\text {gas }}}{\mathrm{H}_{2} \mathrm{O}_{\text {sat, }} \text { ice }}$,

where $\mathrm{H}_{2} \mathrm{O}_{\text {sat, ice }}$ is a function of temperature (Murphy and Koop, 2005). The accuracy of the water vapor instruments was debated during the last decade and thus a couple of studies were carried out to investigate their performance under laboratory and field conditions. The good agreement of the instruments deployed in the field campaigns investigated here is stated by the studies of Fahey et al. (2014), Rollins et al. (2014), and Meyer et al. (2015). These studies provide further details of this group of instruments. Together with the respective uncertainties of the temperature measurements, the accuracy of the $\mathrm{RH}_{\text {ice }}$ observations here is between 10 and $20 \%$.

\subsection{Ice crystal measurements}

Ice crystal number $\left(N_{\text {ice }}\right)$ size distributions were measured during the different campaigns by the cloud spectrometers

$$
\begin{array}{ll}
\text { FSSP-100/300 } & D_{\text {ice }}=3-30 \mu \mathrm{m} \\
\text { CAPS } & D_{\text {ice }}=3-930 \mu \mathrm{m} \\
\text { NIXE-CAPS } & D_{\text {ice }}=3-930 \mu \mathrm{m} \\
\text { 2D-S } & D_{\text {ice }}=15-1280 \mu \mathrm{m} .
\end{array}
$$

$D_{\text {ice }}$ denotes the instruments cloud particle size ranges used for this study, although the respective ranges might be larger (see Table $1 \mathrm{i}-\mathrm{m}$ and respective references). The upper size limits of the instruments differ. However, the largest contribution to the total ice crystal concentration comes from sizes between 3 and about $30 \mu \mathrm{m}$; the concentrations of larger ice particles is in general about three orders of magnitude lower. Hence, the total ice number is covered by most instruments. The 2D-S with the smallest size at $15 \mu \mathrm{m}$ does not record the smallest ice crystals, whose contribution to the total ice crystal number is highly variable and depends on cloud age: in the early stage of a cirrus most of the ice crystals are small, but grow to larger sizes when the cirrus develops.

The quality of cloud spectrometer measurements is - as with humidity - under ongoing discussion. In particular, a boost of smaller ice crystals appearing through shattering of large crystals at the instrument tips was discovered as a source of error in many older observations (see e.g. Krämer et al., 2013, and references therein).

Out of the instruments used here, FSSP-100/300 and CAS during MidCix 2004 (part of the CAPS $=\mathrm{CAS}+\mathrm{CIP}^{3}$ ) might be affected by shattering, since at that time the particles interarrival times could be recorded only with CIP, but not with CAS. To eliminate shattering artifacts, the data set from the CAPS instrument is carefully re-processed for this study by adjusting the size distributions in the overlap range of the two instruments to each other. This was necessary for this campaign since very large cloud particles, up to the CAPS upper size limit $930 \mu \mathrm{m}$, were often present. However, it cannot be ruled out that some shattering influence is still present in the MidCix ice crystal data set, especially since there is an offset in the $N_{\text {ice }}$ measurements in comparison to the other campaigns, which might represent either stronger ice nucleation in faster updrafts or shattering. Nevertheless, taking this offset into account, the MidCix data are a valuable contribution when looking at relative changes of ice crystal concentrations.

A contamination of the measurements from FSSP-100/300 by shattered ice crystals was discussed by Krämer et al. (2009), who stated that a significant effect from shattering is not expected at low temperatures where the ice crystals are smaller, but only at temperatures where the occurrence of larger ice crystals increases. From the analysis of the full data set of this study together with the cirrus simulations we can now conclude that during the campaigns where the FSSP$100 / 300$ were deployed, the ice crystals were not as large as during MidCix or MACPEX, and the ice crystal numbers do not exceed the possible atmospheric range as during those WB-57 campaigns where ice crystal shattering became obvious (e.g., CRYSTAL FACE). Hence, though shattering cannot be completely ruled out, the ice crystal numbers appear to be dominated by natural ice production processes. Thus, we believe that the ice crystal number data set from the Geophysica/Learjet - campaigns is suitable for the study presented here.

The 2D-S (MACPEX 2011) is a new generation cloud instrument, which is equipped with tips and software to minimize shattering effects. However, it starts to record ice crystals at larger sizes than the other instruments $(15 \mu \mathrm{m}$ in com-

\footnotetext{
${ }^{3}$ Two instruments are integrated in the CAPS (Cloud and Aerosol Particle Spectrometer): (1) CAS (Cloud and Aerosol Spectrometer: 0.6-50 $\mu \mathrm{m}$ ) and (2) CIP (Cloud Imaging Probe, CIP:15$930 \mu \mathrm{m})$, (Baumgardner et al., 2001).
} 

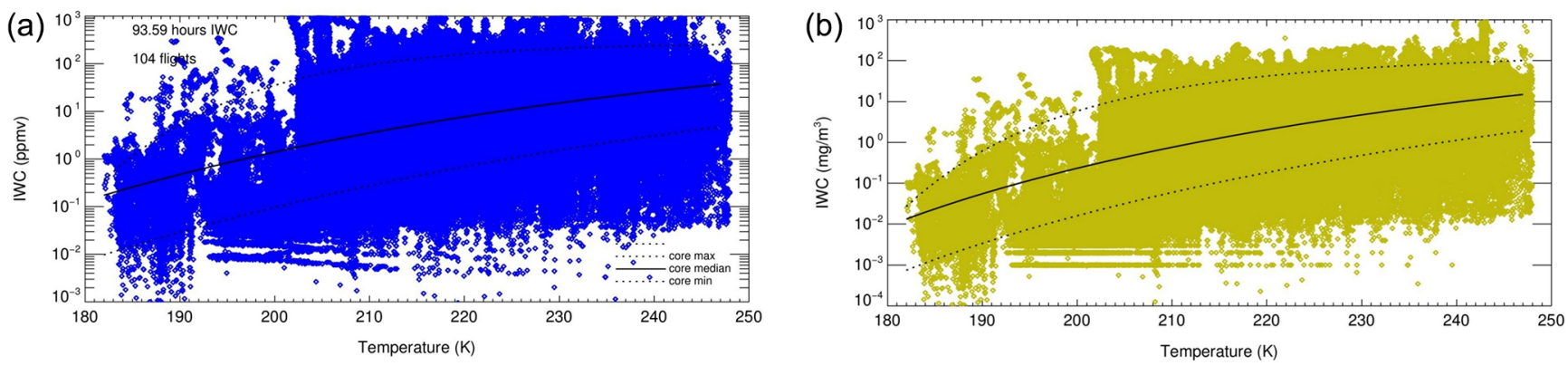

Figure 2. Observations of IWC vs. temperature during the flights shown in Fig. 1. (a) Mixing ratio, (b) concentration. Lines: median IWC (solid) and upper and lower bound of core IWC band (dotted) from observations of Schiller et al. (2008) and Luebke et al. (2013). Total flight distance in clouds was about $67.390 \mathrm{~km} \approx 336.960$ data points (all data are sampled at $1 \mathrm{~Hz}$ ).

parison to $3 \mu \mathrm{m}$, see above; note that technically it starts recording at $5 \mu \mathrm{m}$, but it is recommended not to use the size bin between 5 and $15 \mu \mathrm{m}$ ) and thus the total ice crystal number is lower. Nevertheless, as for the MidCix CAPS data, taking this offset into account, the MACPEX data provide a valuable contribution when looking at relative changes of ice crystal concentrations.

The CIP (part of CAPS used for TC-4) as well as NIXECAPS (ML-CIRRUS 2014) are also new generation cloud instruments so there are no restrictions for these data sets. NIXE-CAPS is a further development of the CAPS instrument; the new features and data evaluation procedure are described in Meyer (2012) and Luebke et al. (2015). One improvement realized for NIXE-CAPS is a modification of the particle inlet of the CAS probe - which is part of NIXECAPS - to minimize shattering. The wall of the inlet entrance is now "knife edged", greatly reducing the area susceptible for ice crystal shattering. Comparisons to particle size and concentration measurements using other instruments such as SMPS, APS, VIPS, SID-3, 2D-S, CPD, made at the cloud chamber AIDA and on aircraft yield good agreement between the probes (Meyer, 2012).

\subsection{Field measurements of IWC and $N_{\text {ice }}$}

The total IWC database from all campaigns shown in Table 1 and Fig. 1 is presented in Fig. 2 as a function of temperature (panel a: mixing ratio, panel b: concentration). Altogether, about $94 \mathrm{~h}$ of flight time was spent in cirrus clouds, thus considerably extending the IWC climatologies of Schiller et al. (2008) (27 h) and Luebke et al. (2013) (38 h). Nevertheless, the median and core IWC - functions derived by Schiller et al. (2008) and confirmed by Luebke et al. (2013) are also valid for the new, extended IWC climatology.

In Fig. 3 the IWC measured during the individual field campaigns are shown. The color code is the ice crystal number $N_{\text {ice }}$. The time of the simultaneous measurements of IWC and $N_{\text {ice }}$ is indicated in the panels and sums up to $85.7 \mathrm{~h}$ for all campaigns, a little less than the $94 \mathrm{~h}$ quoted earlier because of the reduced overall sampling time of $N_{\text {ice. }}$ In
Fig. 3c, the part of the IWC climatology of Schiller et al. (2008) where IWC and $N_{\text {ice }}$ ice particle measurements were performed simultaneously is shown. Simultaneous IWC and $N_{\text {ice }}$ measurements from TC-4 and MidCix are part of the climatology of Luebke et al. (2013) and are here shown in the right column. Recent studies are MACPEX, COALESC, AIRTOSS-ICE, ML-CIRRUS and ACRIDICON-CHUVA. The quite different ranges of IWC and the distribution of $N_{\text {ice }}$ within these ranges will be discussed by comparing the measurements with a simulated cirrus climatology (Cirrus Guide, Sects. 5.1 and 5.2) in Sect. 5.3.

\section{Cirrus simulations}

A simulated cirrus climatology (the Cirrus Guide) is compiled by means of the detailed microphysical box model MAID (Model for aerosol and ice dynamics, Bunz et al., 2008; Rolf et al., 2012), which can be operated along idealized or realistic atmospheric air parcel trajectories.

\subsection{MAID}

MAID simulates parcels of ice clouds where the ice crystals form directly from the gas phase in the temperature range below about $235 \mathrm{~K}$. The ice nucleation processes implemented in MAID are heterogeneous freezing after Kärcher et al. (2006) and homogeneous freezing after Koop et al. (2000). The heterogeneously freezing ice nuclei (IN) can vary in concentration as well as freezing threshold $\left(\mathrm{RH}_{\text {ice }}\right.$, see Fig. 4): $\mathrm{RH}_{\mathrm{ice}}^{\mathrm{MD}}$ represents very efficient IN with a low freezing threshold (MD: mineral dust), while $\mathrm{RH}_{\text {ice }}^{\mathrm{CS}}$ (CS: coated soot) are quite inefficient IN having a high freezing threshold (Gensch et al., 2008). The homogeneously freezing aerosol particles are assumed to be supercooled binary solution particles with a concentration of $300 \mathrm{~cm}^{-3}$ and a mode size of $200 \mathrm{~nm}$. The threshold for homogeneous ice nucleation is higher than that of heterogeneous freezing (see Fig. 4, middle). Thus, in the case where both IN and supercooled 

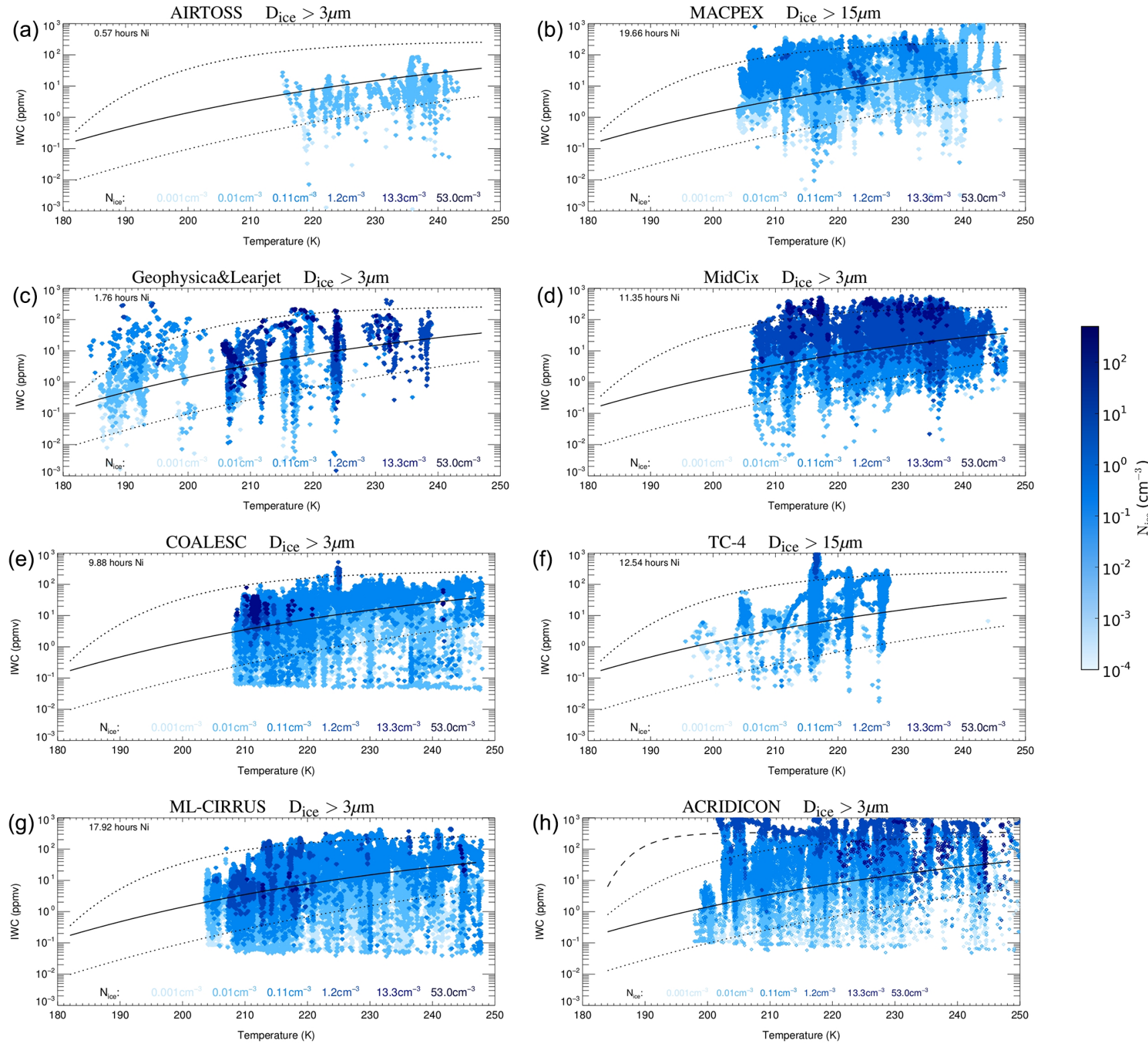

Figure 3. Observations of IWC vs. temperature, color coded by $N_{\text {ice }}\left(=\right.$ total number of ice crystals $\left.>D_{\text {ice }}\right)$. Left column: European field campaigns, right column: US/Brazil field campaigns. Total simultaneous IWC- $N_{\text {ice }}$ measurements $85.7 \mathrm{~h}$. Solid line: median IWC, dotted lines: upper and lower bound of the core IWC band (from observations of Schiller et al., 2008 and Luebke et al., 2013. For instrumentation and campaigns see Table 1 and Fig. 1.

solution particles are present, heterogeneous freezing occurs first.

Once the ice particles have formed at the water activity where the ice nucleates, they grow by diffusional growth in separate size bins (Lagrangian ice particle tracking). When the temperature becomes warmer and the air parcel subsaturates, the ice crystals sublimate and return their water vapor to the air parcel.

Ice crystal sedimentation is treated in MAID following the sedimentation scheme of Spichtinger and Gierens (2009), which uses ice mass and number-weighted terminal velocities (after Heymsfield and Iaquinta, 2000) to simulate sedimentation of ice crystals. The ice flux through the model box is defined by the "sedimentation factor" (sedi-f) and represents the ratio of the flux through the top divided by the flux through the bottom. sedi- $\mathrm{f}=0$ means there is no flux from above into the model box and all ice particles will fall out through the bottom (cloud top), sedi-f $=1$ represents the cloud bottom where the flux from above is equal to the down- 

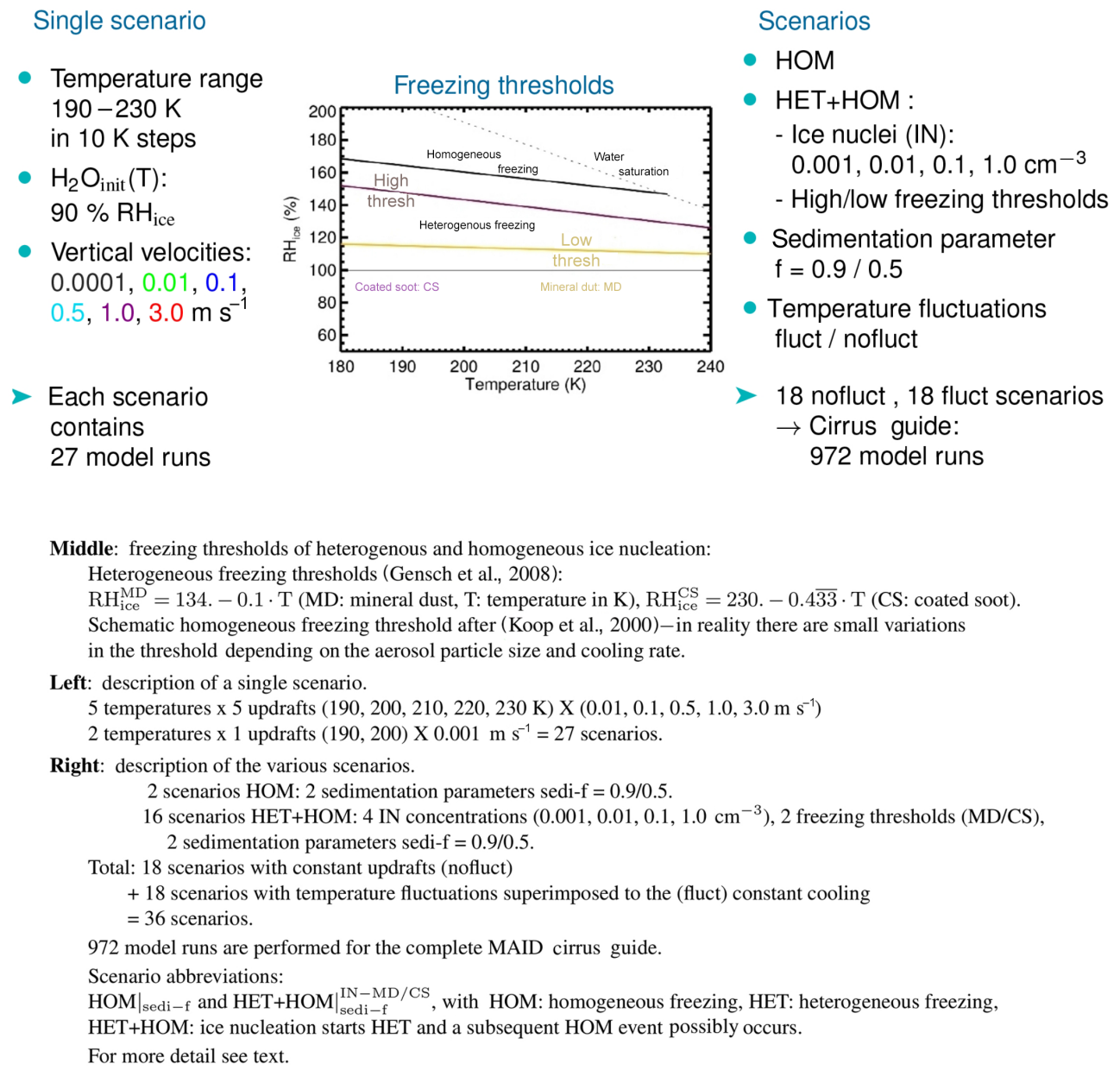

Figure 4. Description of the MAID Cirrus Guide scenarios.

ward flux from the bottom, which simulates a no sedimentation scenario.

The trajectory parcel simulations do not capture dynamical processes such as shear, entrainment, and cloud radiationdynamics interactions, which might reduce the ice number concentrations below the initial values obtained by nucleation Dinh et al. (2014).

\subsection{Cirrus scenarios}

In one MAID Cirrus Guide scenario the cirrus temperature space is scanned in $10 \mathrm{~K}$ steps between 190 and $230 \mathrm{~K}$ (see Fig. 4, left). For each of the five temperatures, simulations with constant vertical velocities of $0.01,0.1,0.5,1.0$, $3.0 \mathrm{~m} \mathrm{~s}^{-1}$ are performed, which are initialized with a water amount of $90 \% \mathrm{RH}_{\text {ice }}(T)$. This sums up to 25 simulations. Further, as at 190 and $200 \mathrm{~K}$ the vertical velocity of $0.001 \mathrm{~m} \mathrm{~s}^{-1}$ is added to enclose the range of large-scale upward motions at the cold temperatures in the Tropical Transition Layer (TTL). Altogether, one scenario contains 27 simulations. They represent the formation and evolution of cir- rus clouds during air parcel ascent, covering the atmospheric range from slow frontal large-scale updrafts up to fast lifting in jet streams or convection. The sublimation phase of the clouds is not considered in the simulations. Also, ice crystals sedimenting into subsaturated air as, e.g., fall streaks are not included in the simulations.

For the complete MAID Cirrus Guide, 36 scenarios (972 model runs) were performed altogether, each varying in the initial and boundary conditions. First of all, pure homogeneous freezing (HOM) or heterogeneous followed by homogeneous freezing (HET + HOM) is allowed to occur. Second, the temperature course of the trajectory can be chosen to be a constant updraft or the updraft can be superimposed with temperature fluctuations. Further, the IN number and freezing threshold and the sedimentation parameter are prescribed for each scenario (see Fig. 4, right).

For the constant updrafts, two HOM scenarios with varying sedi-f ( 0.9 and 0.5 : moderate and strong ice particle sedimentation) are performed, while for HET + HOM 16 scenarios are realized for each combination of four possible IN numbers $\left(0.001,0.01,0.1,1.0 \mathrm{~cm}^{-3}\right.$ : very low to very high), 


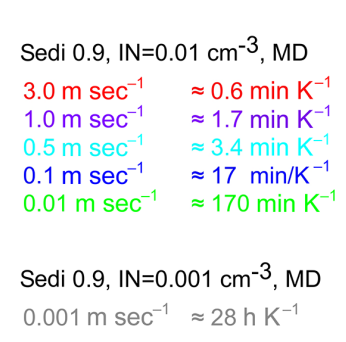

Figure 5. Cirrus scenario HET+HOM $\left.\right|_{\text {sedi-0.9 }} ^{0.01-\mathrm{MD}}$ : simulated evolution of cirrus clouds at different temperatures and varying vertical velocities (see legend). The simulations propagate from right to left, the time of the simulations is indicated in the legend (in min $\mathrm{K}^{-1}$ ). (a) $R_{\mathrm{ice}}$ (lines: min, middle, max $R_{\text {ice }}$ from Krämer et al., 2009), (b) IWC (solid line: median IWC, dotted lines: upper and lower bound of the core IWC band from observations of Schiller et al., 2008 and Luebke et al., 2013), (c) $N_{\text {ice }}$ (lines: min, middle, max $N_{\text {ice }}$ from Krämer et al., 2009), (d) $\mathrm{RH}_{\text {ice }}$.

two different freezing thresholds (MD, CS) and two sedimentation parameters (sedi-f $=0.9,0.5$ ). That means that each constant updraft scenario is simulated 18 times under different conditions, summing up to a total of 486 model runs. The scenarios are abbreviated as follows: the 16 HET + HOM scenarios are HET $+\left.\mathrm{HOM}\right|_{\text {sedi-f }} ^{\mathrm{IN}-\mathrm{MD} / \mathrm{CS}}$, the two pure homogeneous freezing scenarios: HOM $\left.\right|_{\text {sedi-f. }}$.

Finally, the 18 scenarios are repeated by superimposing temperature fluctuations on the constant vertical velocities. The fluctuations are superimposed with five different frequencies $\left(2 \times 10^{-4}, 8 \times 10^{-4}, 2 \times 10^{-3}, 4 \times 10^{-3}, 8 \times 10^{-3} \mathrm{~Hz}\right)$ to cover those fluctuations significant for cirrus formation and to reproduce the typical turbulence spectrum found in the atmosphere. The amplitudes are statistically distributed, whereas the maximum amplitudes increases with height and range from $0.3 \mathrm{~K}$ for the slowest constant vertical velocity to $4 \mathrm{~K}$ for the fastest constant vertical velocity. The frequency spectra and the resulting power spectral density (PSD) are in accordance with Kienast-Sjögren et al. (2015) and also with in situ measurements of temperature fluctuations during several aircraft campaigns (e.g. MACPEX, see Jensen et al., 2013b).
We would also like to mention that the computer time needed for the complete MAID Cirrus Guide sums up to several weeks where multiple PCs are operated simultaneously. The reason is the exact partitioning of the water vapor between gas and solid phase using the different water vapor partial pressures.

\section{Cirrus Guide: microphysical properties}

\subsection{A selected cirrus scenario}

As an example, Fig. 5 shows the Cirrus Guide scenario HET $+\mathrm{HOM}||_{\text {sedi }-0.9}^{0.01-\mathrm{MD}}$, which we consider as the "middle case" with assumed mean IN conditions of $0.01 \mathrm{~cm}^{-3}$, MD, and a moderate sedimentation of sedi-f $=0.9^{4}$. In Fig. $5 b$ IWC is plotted vs. temperature in the same way as the observations shown in Fig. 2. Figure 5a, c shows the respective ice

\footnotetext{
${ }^{4}$ Here and in the rest of our study we present the results of our simulations with constant updraft ("nofluct"), since the cirrus evolution can be seen more clearly in these scenarios. In Sect. 4.3 it is shown that the general cirrus patterns are well represented by the "nofluct" simulations.
} 
crystal numbers $N_{\text {ice }} /$ mean mass radii $\left(R_{\text {ice }}\right)$ together with minimum, middle and maximum $N_{\text {ice }} / R_{\text {ice }}$ lines derived by Krämer et al. (2009) from observations ${ }^{5}$. The $\mathrm{RH}_{\text {ice }}$ development of the scenarios is shown in Fig. 5d, together with the saturation line and the homogeneous freezing threshold. The simulations run from right to left in the figure (indicated by the arrow), starting at the highest temperature and cool further with the respective vertical velocity. The simulation time with temperature is indicated in the legend (in $\min \mathrm{K}^{-1}$ ).

The first impression from Fig. 5 is that the simulated IWC climatology is well within the bounds of the observations (see Fig. 3). $\mathrm{RH}_{\text {ice }}$ ranges between saturation and the homogeneous freezing threshold as expected (subsaturation is not expected here since the simulations represent the cooling phase of the cirrus and evaporation was not considered). However, $N_{\text {ice }}$ exceeds the range of observations for fast updrafts and falls below for slow updrafts. For all scenarios (including those not shown here), $N_{\text {ice }}$ does not change in fast updrafts but varies more in slow updrafts.

A reason that the high $N_{\text {ice }}$ are above the maximum line of the observations is that the fast updrafts producing thick cirrus clouds with many ice crystals have a lifetime on the order of only minutes. They may live longer in multiple repeated cycles, such as in case where they are formed in stationary waves like leewave cirrus downstream of mountains. Nevertheless they are small-scale phenomena and thus there is a low probability that they will be sampled by aircraft, unless they are deliberately targeted, and might not be present in the in situ data sets. In the TTL, where gravity waves caused by convection from below might produce a larger number of ice crystals, the ice nucleation is stalled since the waves are so short that the updraft is reversed before all ice crystals are produced (see also Spichtinger and Krämer, 2013; Dinh et al., 2016).

$N_{\text {ice }}$ below the minimum line do exist, the minimum line derived by Krämer et al. (2009) represents the lower detection limit of the older instruments (FSSP with time resolution of $2 \mathrm{~s}$ ). These lines are under revision based on more observations with advanced cloud probes.

The second important message from Fig. 5, representative for all scenarios of the Cirrus Guide, is that the simulations can generally be grouped by vertical velocities: red, purple and turquoise (fast updraft) on the one hand, and blue, green and gray (slow updraft) on the other hand. The first group of scenarios achieve high IWCs, high $N_{\text {ice }}$ and rapidly decreasing $\mathrm{RH}_{\text {ice }}$ after ice nucleation, while the second group is characterized by low IWC and $N_{\text {ice }}$ but higher $\mathrm{RH}_{\text {ice }}$. A more detailed look into cirrus microphysics in the temperature parameter space is given in the next section.

\footnotetext{
${ }^{5}$ The mean mass radius $R_{\text {ice }}=\mathrm{IWC} / N_{\text {ice }}$ is used for the representation of the model results for particle size, because it is comparable to the established cloud effective radius $R_{\text {eff }}$.
}

\subsection{Cirrus microphysics along selected trajectories}

To provide a better understanding and a clearer view of cirrus microphysics in the temperature parameter space, some trajectories of cirrus formation and development are selected from Fig. 5 and are shown in Fig. 6. Since the cloud processes are much more dependent on updraft than on temperature, we discuss two trajectories at slower updrafts (green line: $1 \mathrm{~cm} \mathrm{~s}^{-1}$ at $230 \mathrm{~K}$ and blue line: $10 \mathrm{~cm} \mathrm{~s}^{-1}$ at $220 \mathrm{~K}$ ), three at higher (turquoise, purple and red: $0.5,1,3 \mathrm{~m} \mathrm{~s}^{-1}$ at $210 \mathrm{~K}$ ) and one at a very low vertical velocity representative of the large-scale ascent in the TTL $\left(0.01 \mathrm{~cm} \mathrm{~s}^{-1}\right.$ at $190 \mathrm{~K})$. The trajectory time proceeds from higher to lower temperatures, as marked by the black arrow. Note here that the times of the scenarios greatly differ: to cool the air by $1 \mathrm{~K}$, 170/17/0.6 min are needed by the green/blue/red air parcels (low/middle/high updrafts). It should be kept in mind that the trajectories apply to the ice nucleation zone of cirrus clouds and not to regions that sedimenting ice crystals fall into. We discuss the two groups of scenarios - slow and fast updraft cirrus - mentioned in Sect. 4.1.

\subsubsection{Slow updraft cirrus}

The green trajectory represents large-scale, very slow liftings associated with a large coverage of longer lived cirrus occurring, e.g., in low or high pressure systems. Detailed inspection of the development of such cirrus, starting at the highest temperature at $90 \% \mathrm{RH}_{\text {ice }}$ (Fig. 6d) show that when the temperature decreases, $\mathrm{RH}_{\text {ice }}$ starts to rise up to the heterogeneous freezing threshold. At this point, heterogeneously formed ice crystals (Fig. 6c) together with a low IWC (Fig. 6b) appear. $\mathrm{RH}_{\text {ice }}$ starts to decrease with decreasing temperature since the ice crystals grow by the uptake of water vapor. When the ice crystals reach a size large enough to fall out of the air parcel, $N_{\text {ice }}$ and IWC strongly decreases again while $\mathrm{RH}_{\text {ice }}$ increases simultaneously due to the decrease in surfaces for water uptake. In this case, the cirrus completely vanishes and thus allows $\mathrm{RH}_{\text {ice }}$ to steadily increase up to the homogeneous freezing threshold where a second, new ice nucleation event occurs. At the very low updraft speed and high cirrus temperature, the number of ice crystals produced by homogeneous freezing is slightly lower than the number of the heterogeneously formed ice particles of the previous cirrus event (note that in the "fluct" scenarios the homogeneously formed $N_{\text {ice }}$ increase slightly due to the superimposed temperature fluctuations). In the remainder of this scenario, as long as the air parcel is cooled, a continuous cycle of ice crystal growth, sedimentation and new homogeneous ice formation proceeds, controlled by decreasing and increasing $\mathrm{RH}_{\text {ice }}$. Notably, during this ongoing sedimentation-ice nucleation cycle $\mathrm{RH}_{\text {ice }}$ stays at a high level. As soon as the cooling is stopped, $\mathrm{RH}_{\text {ice }}$ will quickly relax to saturation (not shown here). The lifetime of this cir- 


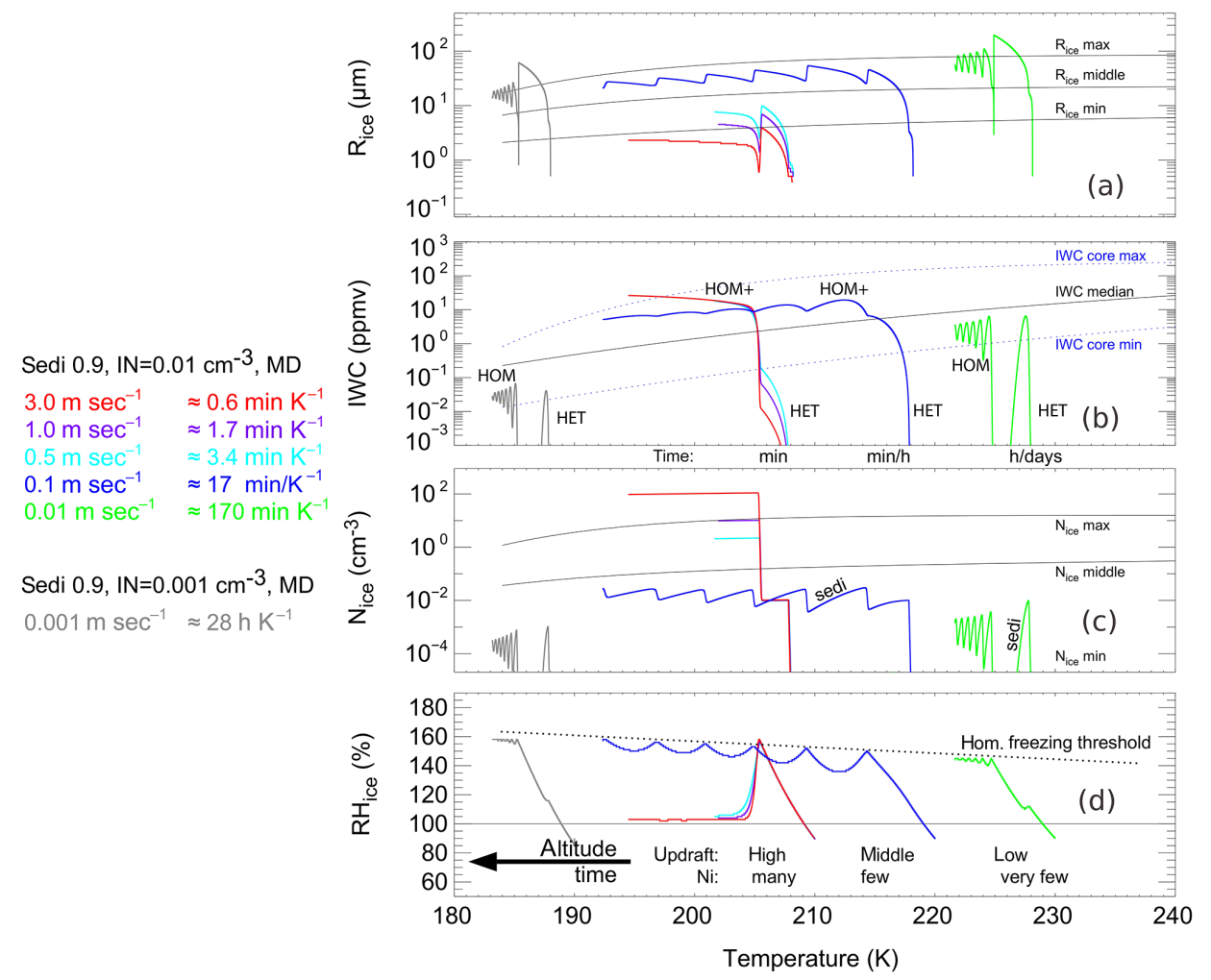

Figure 6. Same as Fig. 5, but only some selected trajectories are shown.

rus type - very low updraft, very low IWC and $N_{\text {ice }}-$ is in the range of hours to days.

The blue lines also show large-scale slow updrafts, but a little faster than the green case. The common updraft range of frontal systems is bounded between these two lines (compare blue and green lines at the different temperatures in Fig. 5). Here, $\mathrm{RH}_{\text {ice }}$ also rises until the heterogeneous freezing threshold is reached and the first ice crystals appear. However, no decrease of $\mathrm{RH}_{\text {ice }}$ caused by depletion of water vapor on the ice surface occurs, but rather the slope of the $\mathrm{RH}_{\text {ice }}$ increase weakens. This is because the updraft is now so large that the increase of $\mathrm{RH}_{\text {ice }}$ by cooling overcomes the water depletion by the ice crystals. Thus, the mean mass radius $\left(R_{\text {ice }}\right)$ of the ice crystals remains smaller than in the green case (Fig. 6a) which is reflected in a weaker sedimentation and higher IWC in the further development of the cirrus. In addition the cirrus does not disappear, but instead a second, homogeneous ice nucleation event occurs - when the freezing threshold is reached - producing somewhat more ice crystals than in the green case due to the larger updraft. Now, the sedimentation-ice nucleation cycle with slightly changing IWC and $N_{\text {ice }}$ and high in-cloud $\mathrm{RH}_{\text {ice }}$ runs as long as the cooling continues. The lifetime of the low updraft, low IWC and $N_{\text {ice }}$ cirrus is in the range of several tens of minutes to hours.

\subsubsection{Fast updraft cirrus}

The turquoise, purple and red trajectories in Fig. 6 illustrate cirrus formed in large updrafts caused, e.g., by gravity waves or orographic waves. Those cirrus typically are of small scale and have a short lifetime of less than an hour. An example is mountain wave cirrus, which indeed can be observed over a longer period; however, such a seemingly longer living cirrus represents continuously formed shortwave cirrus in standing waves (note here that for such cases our simulations represent one cloud parcel passing the wave). The development of fast updraft cirrus, starting again at the highest temperature of the trajectories at $90 \% \mathrm{RH}_{\text {ice }}$ (Fig. 6d) is comparable to the other scenarios - but much faster - for the first, heterogeneous freezing events. However, then $\mathrm{RH}_{\text {ice }}$ quickly increases up to the homogeneous freezing threshold and a strong outburst of homogeneously formed ice crystals appear, with more crystals formed the faster the updraft. Thus, the IWC reaches high values, but the crystals remain small since the available water is distributed equally on the many ice particles. As a consequence, sedimentation is of minor importance in such cirrus and the in-cloud $\mathrm{RH}_{\text {ice }}$ quickly drops down to a dynamical equilibrium close to saturation. 

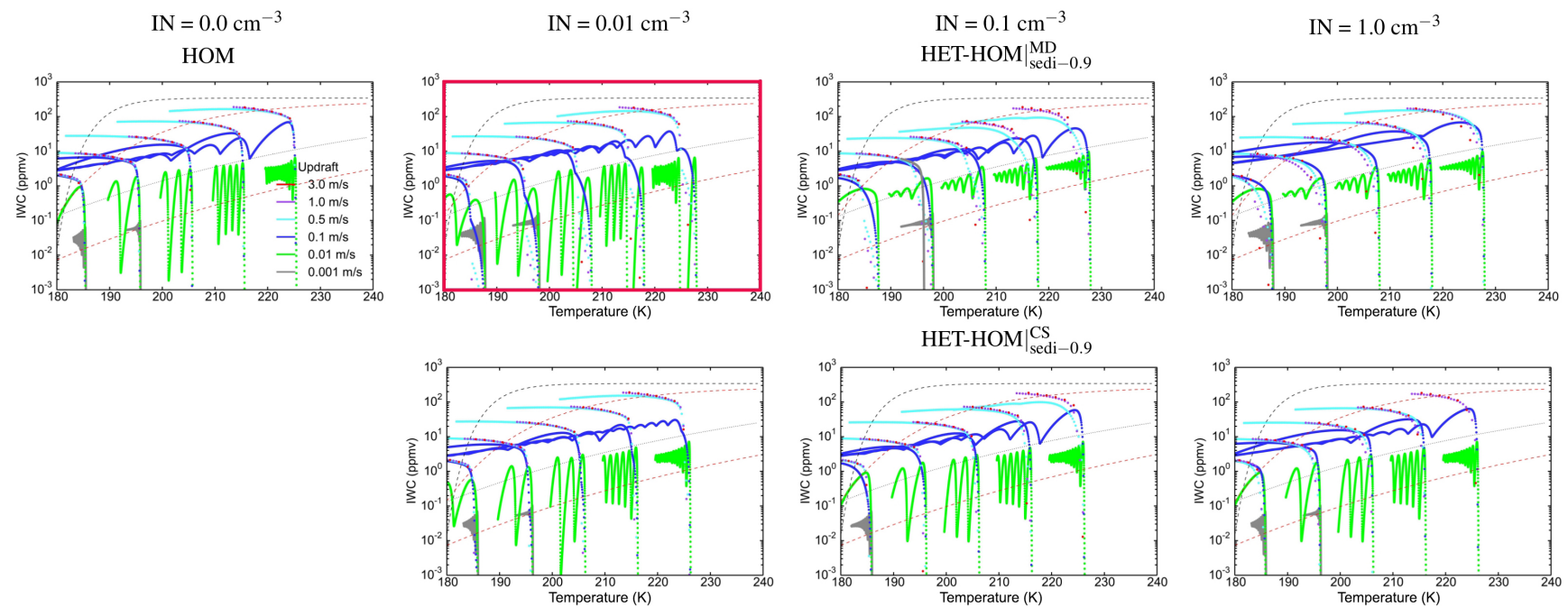

Figure 7. Cirrus scenarios in the IWC-Temperature parameter space for varying initial conditions, color coded by vertical velocities (color code see legend). Columns (from left to right): scenarios HOM $\left(\mathrm{IN}=0.0 \mathrm{~cm}^{-3}\right)$ and HET + HOM $\left(\mathrm{IN}=0.01,0.1,1.0 \mathrm{~cm}{ }^{-3}\right) ;$ top/bottom panels - freezing threshold MD/CS, sedi-f $=0.9$ for all scenarios. Note that the IWC of the different vertical velocities is only weakly dependent on the different initial conditions. Solid line: median IWC, dotted lines: upper and lower bound of the core IWC band from observations of Schiller et al. (2008) and Luebke et al. (2013).

\subsubsection{TTL cirrus}

Cirrus in the very cold tropical tropopause layer are special. They have very low ice crystal numbers found together with high $\mathrm{RH}_{\text {ice }}$ (Krämer et al., 2009; Jensen et al., 2013a), but spikes of high ice numbers embedded in saturation are also reported by Jensen et al. (2013a). Case studies of TTL cirrus observations are also analyzed by Frey et al. (2011, 2014). Spichtinger and Krämer (2013) and recently Dinh et al. (2016) state that low $N_{\text {ice }}$ in high supersaturation are mostly produced by homogeneous freezing in very slow large-scale updrafts, superimposed by very short gravity waves. Due to the shortness of the waves, the ice nucleation process is stalled at the beginning when only a few ice crystals have formed. The IWC is accordingly low. In addition, Dinh et al. (2016) explain the high $N_{\text {ice }}$ in saturation by small variations of water vapor which cause very high supersaturations during the ice nucleation process and thus many more ice crystals.

Though this cirrus formation mechanism is not included in our simulations, we attempt to form these cirrus by assuming heterogeneous-homogeneous freezing in very slow largescale updrafts (gray case; the IN number is only $0.001 \mathrm{~cm}^{-3}$ which is more typical for the TTL). Low $N_{\text {ice }}$ and IWC together with high $\mathrm{RH}_{\text {ice }}$ can be reproduced with these assumptions. Note, however, that the sensitivity case simulated here produces lower $N_{\text {ice }}$ than the average concentration of $0.03 \mathrm{~cm}^{-3}$ reported by Spichtinger and Krämer (2013).

The evolution of the cirrus is comparable to the green case: the first heterogeneously formed cirrus crystals sediment and the next cirrus is formed purely homogeneously since all IN are already consumed. However, the spikes of high ice num- bers embedded in saturation could not be explained with this model approach. Nevertheless, from the data set of Krämer et al. (2009) it seems that low $N_{\text {ice }}$ are the favored state in TTL cirrus. A conclusion for the representation of TTL cirrus by global models - which in most cases overestimate TTL ice crystal numbers - could be that the approach used here might be a useful approximation.

\subsection{A cirrus scenario ensemble}

A representative sampling of all 36 cirrus scenarios in the IWC-T parameter space is shown in Fig. 7. Each panel includes all 27 trajectories, covering the full cirrus temperature and vertical velocity range, as described in Sect. 3 (see Fig. 4). Eight scenarios are shown here: the top row represents simulations with efficient IN like mineral dust (MD, low freezing threshold) and the bottom row inefficient IN like coated soot (CS, high freezing threshold), while the columns show varying IN concentrations. For all scenarios shown here the sedimentation factor is assumed to be moderate (sedi-f $=0.9$ ).

It is obvious from Fig. 7 that the differences between the IN initial conditions (concentration and freezing threshold) do not greatly influence the general pattern of the IWC-T portrayal of cirrus. In other words, it means that the IWC is a quite stable parameter, particularly in comparison with the variability of $N_{\text {ice }}$ and $R_{\text {ice }}$ in dependence to the initial atmospheric conditions (see Sect. 5.3, Fig. 12).

In Fig. 8, the scenario HET + HOM $\left.\right|_{\text {sedi- } 0.9} ^{0.91}$ (same as in Fig. 7: red box; see also Figs. 5 and 6) is shown three times. Figure $8 \mathrm{a}$ depicts the IWCs when temperature fluctuations 

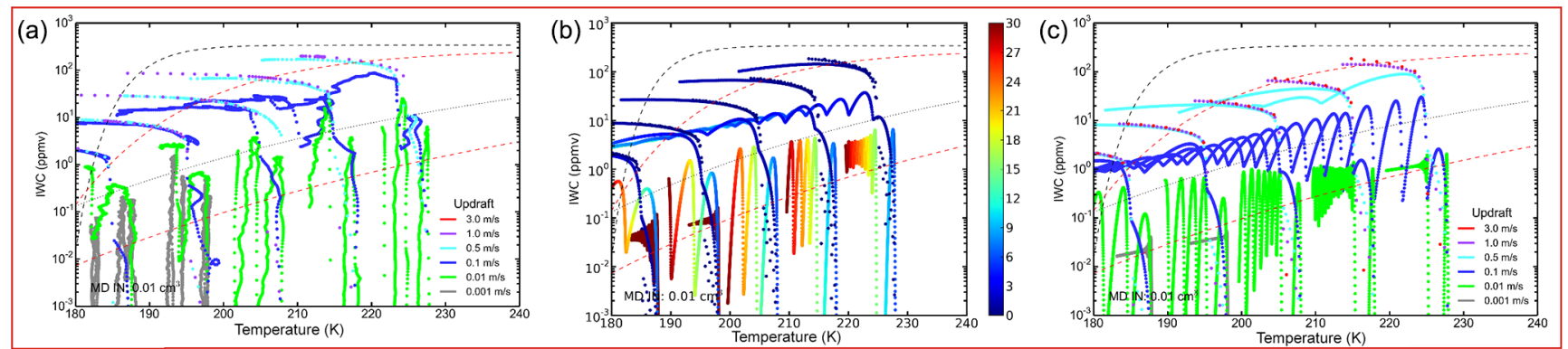

Figure 8. Cirrus scenario HET $+\left.\mathrm{HOM}\right|_{\text {sedi- }-0.9} ^{0.01-\mathrm{MD}}$. Same as in Fig. 7 (red box) (and also Figs. 5 and 6), but (a) with superimposed temperature fluctuations, (b) color coded by time, (c) with strong sedimentation (sedi -0.5$)$.

are superimposed on the constant vertical velocities ("fluct" runs). It can be seen that the general IWC distribution is preserved, looking less structured, while the individual model runs are generally shorter in comparison to the "nofluct" cases (= constant updrafts). The IWC oscillations are parallel to the temperature course, reflecting growing and shrinking ice crystals with increasing and decreasing temperature. The shorter lifetimes can be explained by the fact that the temperature fluctuations contain warming phases so that the cirrus clouds simply evaporate. From Fig. 8b ("nofluct" scenario, color coded by time from blue to red) it can be seen that the parts of the simulations that have disappeared in the "fluct" scenario are cirrus older than about $18 \mathrm{~h}$ (reddish colors). Since the general pattern of IWC evolution is more clear in the "nofluct" simulations, we prefer to show those in this study, though the scenarios with temperature fluctuations better reflect atmospheric conditions.

Next, in Fig. 8c the scenario "nofluct" is shown again, but with enhanced sedimentation (sedi-f $=0.5$ ). Here, a decrease of IWCs can be seen, in particular at warmer temperatures, where the ice crystals are large and preferentially fall out. However, from comparison of the Cirrus Guide scenarios with the meteorological situations found in the observations (see Sect. 5.3), we can conclude that the observations are better represented by the simulations with moderate sedimentation (sedi- $\mathrm{f}=0.9)$.

\section{Cirrus Guide: cloud types}

First of all, we remind the reader that the ice clouds represented in the Cirrus Guide are "in situ origin cirrus". This means that this type of ice clouds is formed "in situ" in the temperature range below about $235 \mathrm{~K}$ directly from the gas phase. The reason for being so specific will become obvious in the following subsections.

\subsection{In situ origin cirrus in slow and fast updrafts}

From the previous sections we conclude that two types are not only found in selected trajectories (Sect. 4.2), but are a general feature of mid-latitude in situ origin cirrus (205$235 \mathrm{~K}$, Sect. 4.3).

\subsubsection{Slow updraft cirrus}

The first type is characterized by slow updrafts, producing low-middle IWCs which consist of low-middle $N_{\text {ice }}$ with middle-to-large $R_{\text {ice }}$ (see black solid and dotted lines in Fig. 5). Sedimentation plays a crucial role by controlling the development of microphysical properties and the in-cloud supersaturation: in the HET part of the "slow updraft cirrus", $\mathrm{RH}_{\text {ice }}$ lies between the heterogeneous and homogeneous freezing threshold, while in the later HET + HOM part $\mathrm{RH}_{\text {ice }}$ remains slightly below the homogeneous freezing threshold. The formation mechanism of this cirrus type starts with HET freezing that is followed by a second, HOM ice nucleation event (since all IN are already consumed) if the cooling phase is long enough and temperature fluctuations do not cause a HOM freezing event earlier. Thus, the slow updraft cirrus have a possibility to remain as purely HET formed ice clouds. On the other hand, purely HOM formed cirrus also only appear in the long lasting, slow updraft cirrus: they evolve after the earlier HET cirrus have disappeared by sedimentation. The frequency of occurrence of these cirrus is unknown.

\subsubsection{Fast updraft cirrus}

The second type are "fast updraft cirrus" with high ice crystal numbers and IWCs. Sedimentation does not play a great role in this cirrus type and thus the in-cloud $\mathrm{RH}_{\text {ice }}$ quickly reduces to saturation. The formation mechanism of this cirrus type is also HET + HOM, but it is dominated by HOM ice formation.

\subsection{Cirrus microphysics in the IWC-T parameter space}

We can conclude that cirrus microphysics is visible in the IWC-T parameter space up to a certain degree, i.e., depicting measurements of IWC vs. temperature gives an impression of the nature of observed cirrus without the need of more detailed microphysical measurements. This is summarized in 


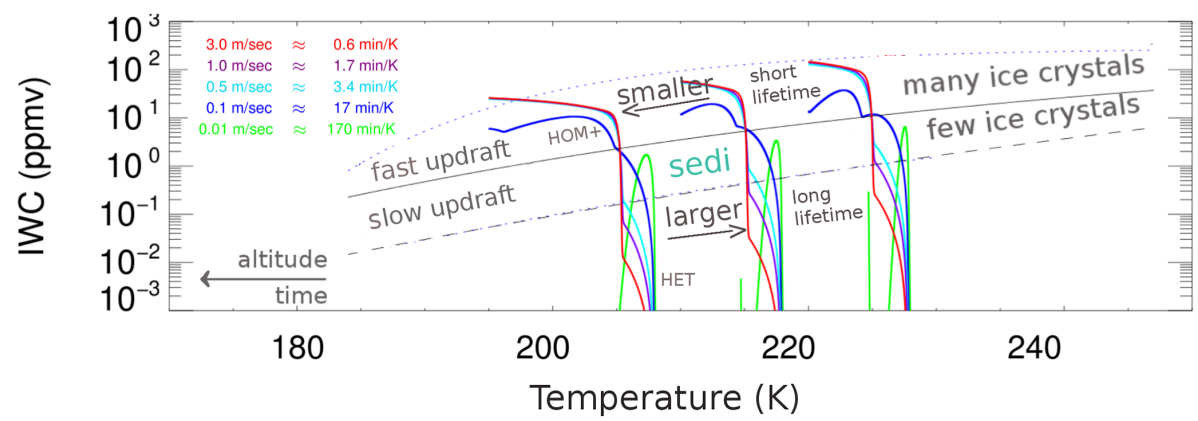

Figure 9. Sketch of the MAID in situ Cirrus guide: two classes of in situ cirrus clouds are identified in the IWC-T parameter space. (1) IWCs below the median IWC line (Schiller et al., 2008; Luebke et al., 2013) mostly stem from slow updraft cirrus. They consist of few, but large ice crystals which are larger the warmer the cirrus is. The first part of these cirrus is determined by HET freezing (indicated in the figure). If the clouds life time is long enough, HOM freezing also starts. Due to the low updrafts, the number of ice crystals produced by HOM freezing does not greatly differ from the HET nucleated ice crystals. Thus, in slow updraft regions the difference in microphysics between HET and HOM formed cirrus is small. (2) High IWCs above the median IWC line are mostly produced by fast updraft cirrus. The time of the HET cirrus part at low IWC is short since the HOM freezing pushes the IWC quickly above the median line. With their large number of small, non-sedimenting ice crystals, these cirrus are microphysically very different from the slow updraft cirrus.

the sketch shown in Fig. 9, where we plotted some of the MAID scenarios together with the median, core and maximum IWC-lines to guide the eye.

IWCs below the median line mostly stem from slow updraft cirrus in low- or high-pressure systems. They consist of a few, but large ice crystals which are - due to the increasing amount of available water vapor - larger the warmer the cirrus is. The first part of these cirrus is determined by HET freezing. However, if the cloud life time is long enough, HOM freezing will start as well. Due to the slow updrafts, the number of ice crystals produced by HOM freezing is on the same order of magnitude as the HET nucleated ice crystals and thus also have low IWCs. We emphasize here that in slow updraft regions the difference in microphysics between homogeneous and heterogeneous freezing is small. In this cirrus type, sedimentation plays an important role, controlling the microphysical properties and might produce fallstreaks, which causes some vertical redistribution of water.

High IWCs above the median line are mostly produced by fast updraft cirrus caused by atmospheric waves. The cirrus is only briefly at low IWC during the HET phase since the HOM freezing quickly pushes the IWC above the median line. With their large number of small, non-sedimenting ice crystals, these cirrus are microphysically very different from the slow updraft cirrus.

An impression of the radiative properties in terms of extinction of the two cirrus types is given in Fig. 12d, where the ice crystal number $N_{\text {ice }}$ is shown vs. the corresponding mean mass radius $R_{\text {ice }}$ for all temperatures. The IWCs are plotted as black isolines. Figure 12b shows the same, but with color coded IWC, in Fig. 12c the color code is vertical velocity. The extinction of all simulated cirrus is calculated from the empirical relationship between IWC and extinction provided by Gayet et al. (2004). Those cirrus with a low number of large crystals (slow updraft, low IWC, see Fig. 12c and b) have a small extinction, i.e., they are optically thin, while the cirrus with the many small ice crystals (fast updraft, large IWC, see Fig. 12c and b) have larger extinctions and are optically thicker.

The majority of cirrus clouds in the atmosphere are of the first "slow updraft" type, i.e., they appear on a larger scale and have a longer lifetime, while the second "fast updraft" type occurs less frequently since the fast updrafts are limited in space and time (note here that "fast updraft" does not include convection in the simulations; "convective" or "anvil" cirrus will be addressed later in Sects. 5.4 and 5.5).

\subsection{Comparison of simulations and observations}

In this section, we compare observed and simulated cirrus clouds to demonstrate that the simulated Cirrus Guide shown in Fig. 9 is confirmed by measurements and thus is indeed appropriate for an impression of the cirrus microphysics.

\subsubsection{IWC-T parameter space}

In Fig. 10a the simulated Cirrus Guide is shown again, but color coded by the ice crystal number $N_{\text {ice }}$. It can be seen that in the simulations few ice crystals are present below the median IWC line (light blue), while more and more (darker blue) $N_{\text {ice }}$ appear with increasing IWC. As described in Sect. 3.2, the simulations in the Cirrus Guide represent the formation and evolution of cirrus as long as the air parcels are cooled. Subsaturated environments with shrinking ice crystals or fallstreaks are not included. Thus, there is the possibility that a part of the small IWCs in the observations are not comparable to those simulated in the Cirrus Guide.

From all of our measurements, we have compiled a data set that compares best to the Cirrus Guide (Fig. 11). For that 

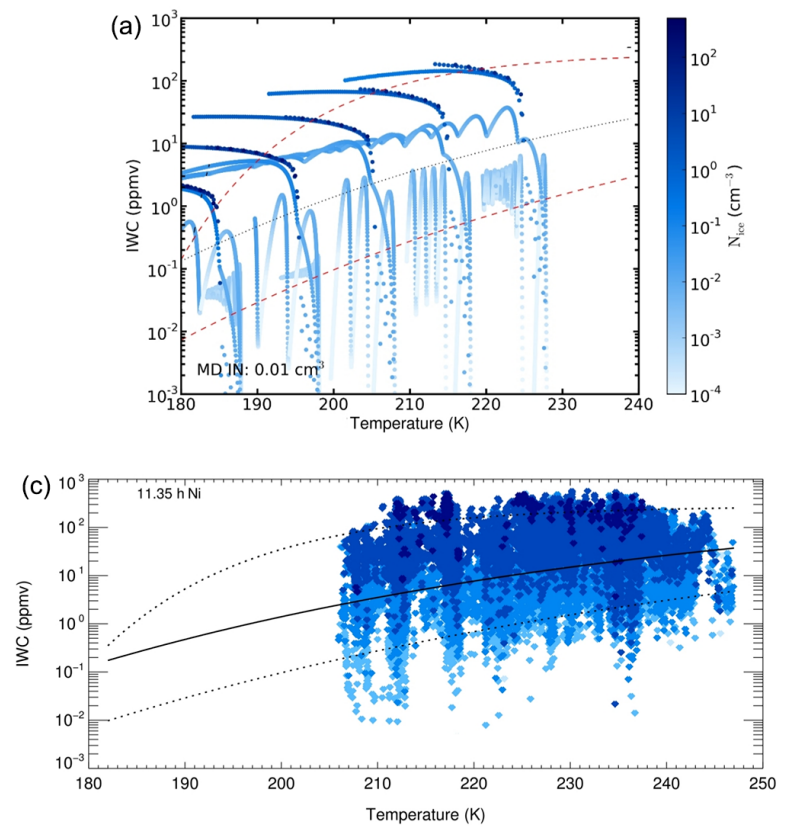
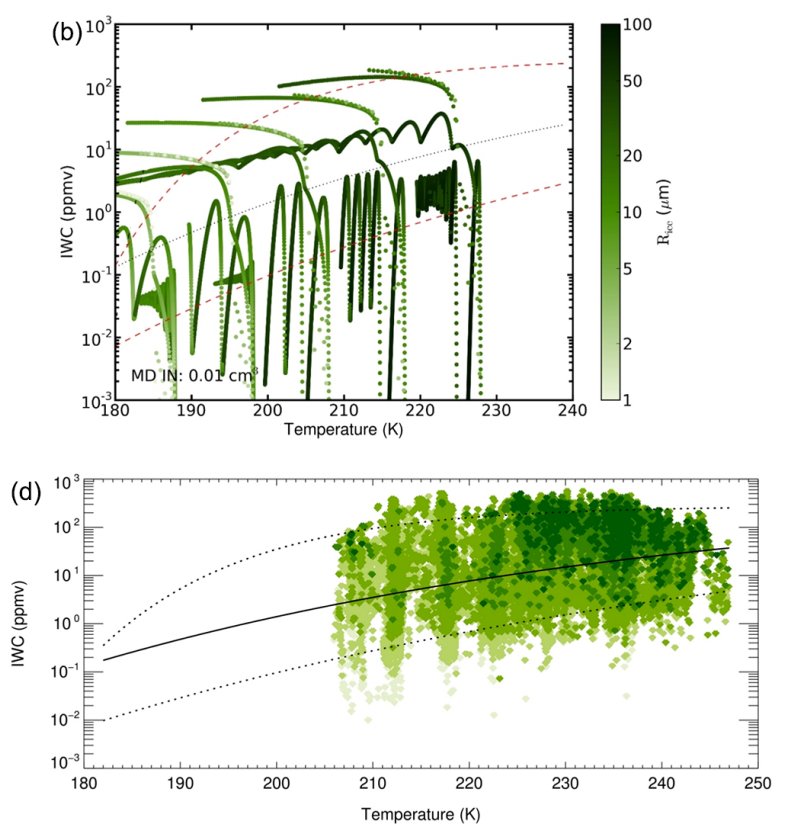

Figure 10. IWC colored by $N_{\text {ice }}($ left $)$ and $R_{\text {ice }}\left(\right.$ right); (a, b) MAID scenario HET + HOM $\left.\right|_{\text {sedi- }-0.9} ^{0.01-\mathrm{MD}}$, (c, d) observations from MidCix.

purpose, we used only measurements where $\mathrm{RH}_{\mathrm{ice}}>95 \%$. Also, only those campaigns where ice crystals with diameters larger than $3 \mu \mathrm{m}$ were measured and ice crystal shattering effects are minimized were considered (Geophysica - TTL flights, COALESC, AIRTOSS-ICE, ML-CIRRUS; ACRIDICON 2014 fits these requirements but is not considered since it is nearly entirely driven by strong convection). Comparing Fig. 10a (simulations) with Fig. 11 (observations) yields in general the same $N_{\text {ice }}$ pattern in the simulations and the measurements. This means that the simulations are able to represent the increasing ice crystal number with increasing IWC seen in the measurements. Some dots in darker blue colors are visible in the observations, particularly at higher IWC. They can be traced back to situations with higher vertical velocities and thus represent the rare fast updraft cirrus discussed above.

Looking back now at the full data sets of the individual campaigns (Fig. 3), it can be seen that the decreasing $N_{\text {ice }}$ with decreasing IWC is visible in all field campaigns, even when the measurements are under suspicion of shattering effects. This suggests that in the respective data sets shown here, the amount of small artifacts of shattered ice crystals is not large enough to overlay the microphysical cirrus properties. Thus, we look now in more detail at the different field experiments.

We start with the AIRTOSS-ICE campaign (Fig. 3a). Here, one can see that very low $N_{\text {ice }}$ concentrations were observed. The measurements were performed in August and September 2013 above the German North Sea (for geographical regions see Fig. 1) under Indian summer conditions, which

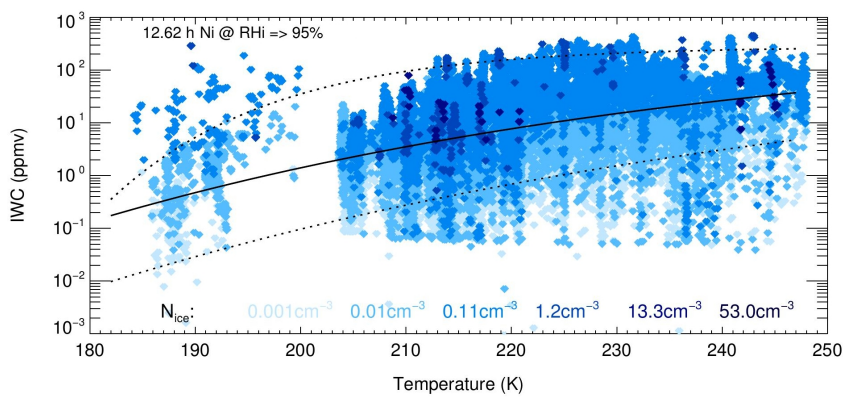

Figure 11. IWC colored by $N_{\text {ice }}$ for (1) $\mathrm{RH}_{\text {ice }}>95 \%$, which compares best to Cirrus Guide, and (2) those campaigns with PSDs for ice crystals with $D>3 \mu \mathrm{m}$ and minimized ice crystal shattering effects (Geophysica - TTL flights, COALESC, AIRTOSS-ICE, MLCIRRUS; ACRIDICON 2014 is not considered since it is nearly entirely driven by strong convection).

implies that very low vertical updrafts associated with highpressure systems prevailed during the flights.

The IWC climatology from the Geophysica/Learjet measurements between 1999 and 2006, which covers a large geographical range, is shown in Fig. 3c. Measurements in the TTL $(T<200 \mathrm{~K})$ are contained here, with very low $N_{\text {ice }}$ detected at low IWCs - probably formed in very slow updrafts - but also higher $N_{\text {ice }}$ together with high IWCs formed at higher updrafts. These two types of cirrus are also observed during the Global Hawk ATTREX mission in the TTL (Jensen et al., 2013a). Additionally, very high $N_{\text {ice }}$ (dark blue points) can be seen above the median IWC line in the measurements at temperatures larger than about $205 \mathrm{~K}$. Closer 
inspection of the meteorological situation shows that these measurements were performed downstream of the Norwegian mountains at very high vertical velocities and can be interpreted as leewave cirrus. High $N_{\text {ice }}$ below the median IWC line in this temperature range might be a result of ice crystal shattering.

Calmer meteorological conditions prevailed during COALESC (Fig. 3e) in spring 2011 over the Southern part of the UK. This is visible in the quite smooth color gradient, only disturbed by a dark blue patch at higher IWC between 210 and $215 \mathrm{~K}$. These high ice crystal numbers represent very fresh contrails, which were chased during one flight. The grouping of the points in a small temperature range reflect the cruising altitude of passenger aircraft.

ML-CIRRUS (Fig. 3g) took place in spring 2014 over Europe. Here, low- and high-pressure systems, some jet stream cirrus as well as contrails and aviation induced cirrus were probed. Nevertheless, the pattern of $N_{\text {ice }}$ increasing with IWC is also visible here. As during COALESC, a block of higher $N_{\text {ice }}$ at higher IWC around $210 \mathrm{~K}$ is found, though $N_{\text {ice }}$ is a little lower here. They represent older contrails and aviation induced cirrus which were omnipresent in the cirrus probed over Central Europe.

Next, we discuss the two campaigns over the US continent, MACPEX (2011) and MidCix (2006), TC-4 (2007) over Costa Rica and ACRIDICON-CHUVA (2014) over Brazil (Fig. 3, right column). Again, the general pattern of $N_{\text {ice }}$ increasing with IWC can clearly be seen in the measurements, though TC-4 is in general on the lower IWC side in comparison to MidCix and MACPEX and especially ACRIDICONCHUVA, which reaches very high IWCs. The meteorological situations for MidCix and MACPEX, which took place in the same region (Southern US continent), were mostly determined by mesoscale convective systems with high updrafts, while ACRIDION-CHUVA represents smaller scale tropical deep convection.

What is surprising for ML-CIRRUS, MidCix and MACPEX and particularly ACRIDION-CHUVA are the many data points at very high IWCs: high IWCs should appear from fast updrafts, which are discussed as small scale features that do not appear frequently (see Sect. 5.1). To further investigate this, we have plotted the simulated Cirrus Guide again, now color coded by the mean mass size $R_{\text {ice }}$ of the ice crystals in Fig. 10b. It is seen that $R_{\text {ice }}$ is largest (dark green) at low IWCs and high temperatures. For comparison the same plot type is shown for MidCix Fig. 10d (for consistency the MidCix IWC colored by $N_{\text {ice }}$ is shown in Fig. 10c). Conversely to the simulations, the largest ice crystals appear at the highest IWCs in the MidCix observations. Seemingly, these frequently appearing cirrus with high IWCs and large ice crystals are not present in the simulations of in situ origin cirrus. They represent a different type of ice clouds originating in liquid droplets, which will be further discussed in Sect. 5.4.

\subsection{2 $\quad N_{\text {ice }}-R_{\text {ice }}-$ IWC parameter space}

For the ML-CIRRUS (2014) campaign, it was possible to extract the in situ origin cirrus from the observations by analyzing the cloud history along backward trajectories (for more detail see Luebke et al., 2015). Hence, this data set is particularly suitable for comparison with the MAID simulations. For that purpose, we show a different type of plot (introduced already in Sect. 5.2), including the information of IWC, $N_{\text {ice }}$ and $R_{\text {ice }}$ all at once. In Fig. 12 the ice crystal number $N_{\text {ice }}$ is plotted as function of $R_{\text {ice }}$. In the upper row, the color code is IWC and the black lines are isolines of constant IWC. Figure 12a shows the observations during ML-CIRRUS (2014) and in Fig. 12b the Cirrus Guide simulations of all "fluct" scenarios (including temperature fluctuations, see Sect. 3) are shown. For a better interpretation, the same plot is shown in Fig. 12c, now color coded by vertical velocity in the same colors used in previous figures. Fig. $12 \mathrm{~d}$ is color coded by extinction (see Sect. 5.2).

Inspection of the Cirrus Guide vertical velocity plot (Fig. 12c) shows that high updrafts (red dots) can produce ice crystals smaller than $10 \mu \mathrm{m}$ (mass mean radius) with concentrations between 5 and $500 \mathrm{~cm}^{-3}$. With decreasing updraft, $N_{\text {ice }}$ decreases to values down to $10^{-4} \mathrm{~cm}^{-3}$ while $R_{\text {ice }}$ grows to maximum sizes of $100 \mu \mathrm{m}$. Note that $R_{\text {ice }}$ is also an indicator for cirrus age, the larger the mass mean size, the older the cloud. Comparing with the IWC plot (Fig. 12b) it can be seen that lower vertical velocities are related to lower IWCs with fewer, larger ice crystals and higher updrafts with higher IWC and more, smaller ice crystals (as also shown in Sect. 5.2).

From a comparison of the observations (Fig. 12a) with the simulations (Fig. 12b), it is evident that the observed cirrus are located well within the bounds of the simulations. The range of values covered by the observations is smaller because they represent mid-latitude cirrus clouds with temperatures between about 205 and $235 \mathrm{~K}$ and mostly slow updrafts, while the simulations represent the full cirrus climatology including colder temperatures and higher vertical velocities. The observed concentrations of small ice crystals 5$20 \mathrm{~cm}^{-3}$ are mostly related to the contrails noted already in the previous section. Also, some meteorological situations with higher updrafts were probed during the campaign, leading to observations with a maximum $N_{\text {ice }}$ of $5 \mathrm{~cm}^{-3}$. The maximum sizes of the observed cirrus particles are smaller than in the simulations, which points to a shorter cirrus lifetime in the atmosphere than in the simulations. Also, some thicker cirrus (red points between the IWC isolines 200300 ppmv) are detected during ML-Cirrus. However, given the wide range of different parameters influencing the cirrus formation and evolution, the good agreement between observations and simulations demonstrates that with the help of the Cirrus Guide an interpretation of cirrus observations is possible in greater depth. 

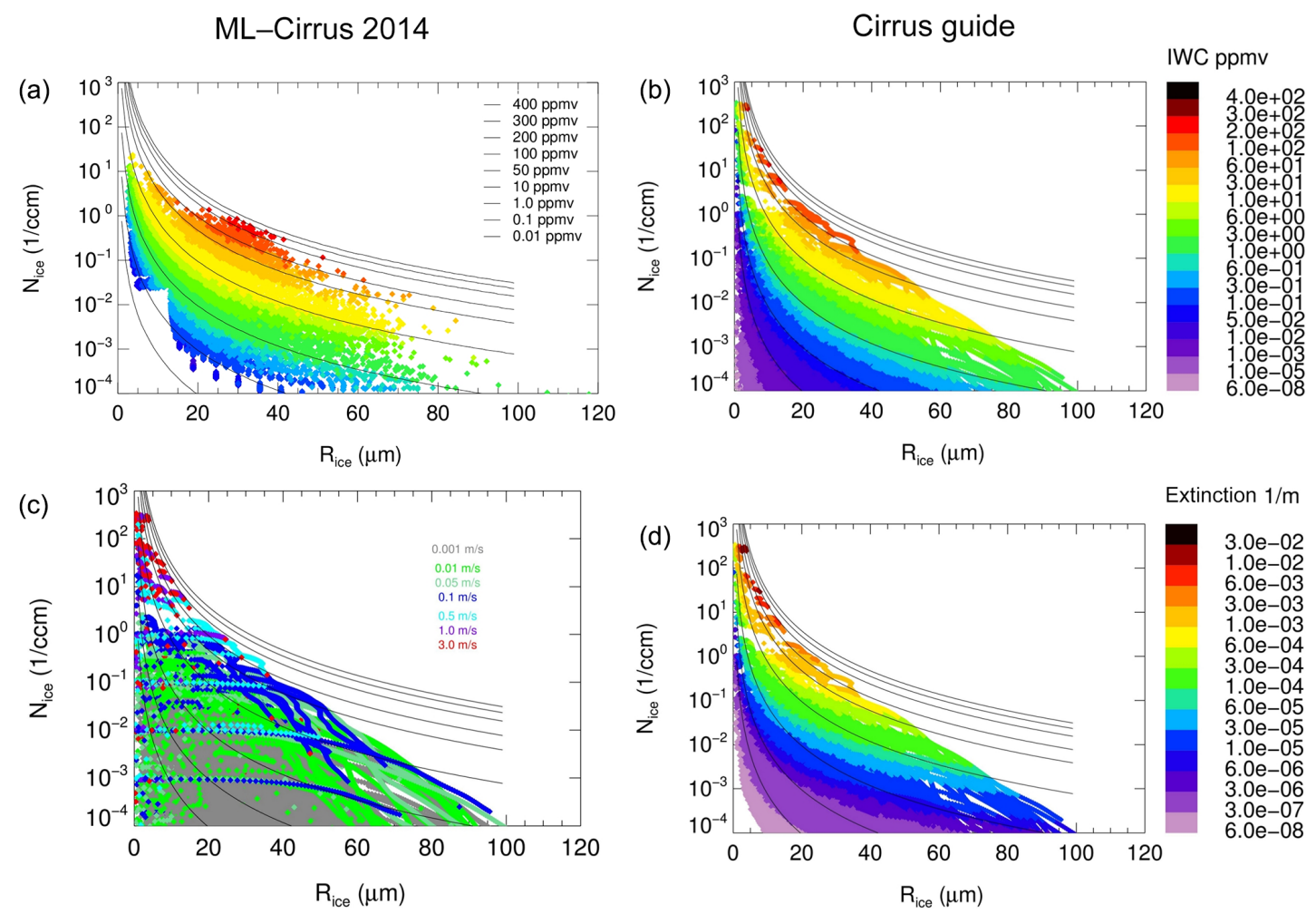

Figure 12. $N_{\text {ice }}$ vs. $R_{\text {ice }}$ (a) Observations of in situ cirrus during ML-CIRRUS 2014 - color code IWC, black lines are IWC isolines. The other panels show the simulated Cirrus Guide: (b) color code IWC, (c) color code vertical velocity, (d) color code extinction. The simulations contain all scenarios including temperature fluctuations ("fluct", see Sect. 3).

\subsection{Liquid origin cirrus}

In the last paragraph of Sect. 5.3.1 it is mentioned that high IWCs above the median IWC together with large ice crystals (Fig. 10) are not represented in the Cirrus Guide. Nevertheless, this type of cirrus is found in the observations, especially during MidCix, MACPEX and ACRIDICONCHUVA, as well as in the other campaigns shown in Fig. 3 (except AIRTOSS-ICE). Here, a larger number of very high IWC are detected than was expected based on the MAID simulations. From further analysis, relating meteorological situations to cirrus types, it can be concluded that these high IWC cirrus stem from lower altitudes and are not produced by in situ ice nucleation directly from the gas phase like in our simulations (for detail see Luebke et al., 2015). Instead, they are formed by heterogeneous freezing of liquid droplets at temperatures $>235 \mathrm{~K}$ or possibly as low as $235 \mathrm{~K}$ by homogeneous drop freezing. The ice crystals were then lifted to the temperature range $<235 \mathrm{~K}$ and are therefore regarded as cirrus clouds. This can happen in regions with mesoscale convective activity (observed during MidCix and MACPEX), but also in warm conveyor belts (observed during ML-CIRRUS). In tropical convective systems, which are observed in this study during ACRIDICON-CUVA, this cirrus type is known as "anvil cirrus" or "anvil outflow".
Note that in addition to a high IWC, other indicators for cirrus originating from liquid drops are high $N_{\text {ice }}$ together with the appearance of larger ice crystals (for more detail see Luebke et al., 2015). The high ice crystal concentrations may stem from an originally larger frozen drop number, or from an additional freezing event that may happen on top of the preexisting ice in case the updraft is fast enough. The nucleation mechanism will probably be homogeneous freezing, since the IN are already consumed in the previous liquid cloud. The high supersaturation that is needed can be reached in fast updrafts, when the reduction of $\mathrm{RH}_{\text {ice }}$ by uptake of water on the ice surfaces is less than the $\mathrm{RH}_{\text {ice }}$ enhancement caused by the decreasing temperature.

Altogether, these thick liquid origin cirrus have microphysical, and thus optical, properties quite different from the in situ cirrus formed directly via the gas phase. Further, they appear together with mixed-phase and often liquid clouds below. This is shown in detail for liquid origin clouds stemming from warm conveyor belts in comparison to in situ cirrus observed during ML-CIRRUS by Luebke et al. (2015).

It is a surprising result from this study that these "liquid origin cirrus" seem to appear in the complete cirrus temperature range with a non-negligible frequency. As a consequence, for a complete understanding we recommend devot- 


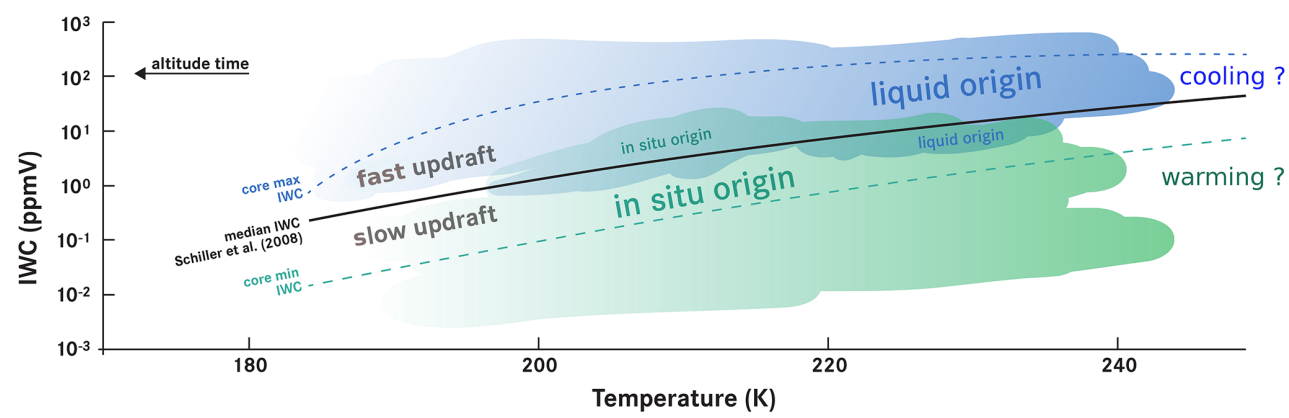

Figure 13. Sketch of in situ and liquid origin cirrus (large letters: high frequency of occurrence, larger ice crystals, stronger sedimentation, longer lifetimes; small letters: low frequency of occurrence, smaller ice crystals, lesser sedimentation, shorter lifetimes). In situ origin cirrus (greenish color): ice crystals form heterogeneously+homogeneously directly from the gas phase. In situ cirrus are preferably thin with lower IWC. They divide in two classes (see also Fig. 9): (1) thin cirrus forming in slow updrafts consisting of few, large ice crystals with a large geographic coverage and a long lifetime, (2) thicker cirrus forming in fast updrafts consisting of many, small ice crystals with a smaller geographic coverage. Liquid origin cirrus (blueish color): ice crystals stem from frozen liquid drops which are uplifted from farther below in the atmosphere into the cirrus temperature range. Liquid origin cirrus are mostly thick with higher IWC and have larger ice crystals than the in situ cirrus (for more detail see Luebke et al., 2015). Their geographic coverage and lifetime depend on the meteorological situation: larger and longer in warm conveyor belts, smaller and shorter in convective systems.

ing further research to assessing their properties and including them in model studies.

\subsection{Comparison with other cirrus classifications}

Cirrus cloud classifications already exist and are used in the literature (e.g. Sassen, 2002; Heymsfield et al., 2002b; Muhlbauer et al., 2014; Jackson et al., 2015). Here we intend to compare our findings of the two in situ origin types and the liquid origin cirrus with the present classifications.

"In situ", "synoptic" and also "lee wave", "gravity wave" or "orographic" cirrus are used as definitions for cirrus cloud forming directly from the gas phase. Since "in situ" is the most common name - and "lee/gravity wave" and "orographic" cirrus are already very specific - we followed this approach in our classification. On the other hand, the term "convective" or "anvil" cirrus is used to classify cirrus clouds representing glaciated, but originally liquid clouds lifted to the cirrus temperature regime in the prevailing updraft. Here, we name this type "liquid origin cirrus", since we found that the lifting of clouds to temperatures $T<-38^{\circ} \mathrm{C}$ happens not only in convective systems connected to anvils, but also in warm conveyor belts, in mesoscale convective systems and even in gravity wave clouds.

Thus, compared to the grouping based on specific meteorological situations, the cirrus classification scheme we present here is based on (i) the formation mechanism (directly ice or frozen liquid droplets), which is tied to the temperature threshold of $-38^{\circ} \mathrm{C}$ below which liquid water does not exist, and, (ii) the vertical velocity, which determines the thickness of the cirrus.

A thorough study on the impact of large-scale dynamics on the microphysical properties of midlatitude cirrus has been performed by Muhlbauer et al. (2014). The study is based on cirrus cloud observations during the field campaign SPARTICUS in 2010 (see also Jackson et al., 2015) in the vicinity of the ARM SGP site (Atmospheric Radiation Measurement, Southern Great Plains) and analysis of atmospheric states using a combination of ECMWF ERA-Interim reanalysis data with continuous observations from a millimeter-wavelength cloud radar.

Four cirrus types are defined by Muhlbauer et al. (2014): (a) ridge-crest, (b) frontal, (c) subtropical jet stream and (d) anvil. Striking differences in the cirrus microphysics (IWC and $N_{\text {ice }}$ ) for different large-scale environments were found in this study. The authors suggest that vertical velocities are a poor predictor for explaining the microphysical variability in cirrus.

Before comparing the findings of Muhlbauer et al. (2014) with this study, we like to note a difference in the observed IWC ranges: here, IWCs between about 0.001 and $\approx 300 \mathrm{mg} \mathrm{m}^{-3}$ are detected in the SPARTICUS temperature range $>210 \mathrm{~K}$ (see Fig. 2b), while in Muhlbauer et al. (2014) the observed IWC range spans from 1 to $\approx 400 \mathrm{mg} \mathrm{m}^{-3}$ (their Fig. 6). From Fig. 2b it becomes obvious that the in situ cirrus in slow updrafts with low IWCs (in general $<1 \mathrm{mg} \mathrm{m}^{-3}$, i.e., below the median IWC line) are barely included in the SPARTICUS observations. Thus, the definitions of "low" and "high" IWCs differ between the two studies: the peaks of the frequency distributions of ridge-crest cirrus are discussed as low IWC $\left(\approx 8 \mathrm{mg} \mathrm{m}^{-3}\right)$ in connection with high $N_{\text {ice }}\left(\approx 0.2 \mathrm{~cm}^{-3}\right)$ (Muhlbauer et al., 2014). However, in the parameter space of the Cirrus Guide, $8 \mathrm{mg} \mathrm{m}^{-3}$ is well into the high IWC range, so the classification would be high IWC and high $N_{\text {icee }}$. Frontal and subtropical jet stream cirrus, which are described by Muhlbauer et al. (2014) to have middle IWC and $N_{\text {ice }}$ are also in the range of high IWC and 
$N_{\text {ice }}$ in the context here. Anvil cirrus have high IWC and $N_{\text {ice }}$ in both studies.

Taking this into account, we can relate (a) ridge-crest to fast updraft in situ origin cirrus - a type of cirrus that is quite rarely found in our observations and (b) frontal cirrus most probably to liquid origin cirrus in slower frontal updrafts (like WCBs in our study). Subtropical jet stream cirrus (c) also seem to be of liquid origin - because of the higher IWCs - with a possible subsequent weak in situ homogeneous freezing event, and, (d) anvil cirrus are classified as liquid origin in fast updrafts. With respect to a vertical velocity classification, we think that the lack of significant differences detected by Muhlbauer et al. (2014) between the cirrus types is a consequence of observing cirrus classes that are all situated in the fast updraft range above the IWC median. The slow updraft in situ cirrus classified in this study exhibit IWCs below the median IWC line and are not included in Muhlbauer et al. (2014).

Altogether, the four classifications provided by Muhlbauer et al. (2014) for the high IWC range agree very well with the cirrus classes of this study. They are more specific than the two types provided here (fast updraft in situ or liquid origin cirrus), which we have not further specified due to a lack of observations of fast updraft in situ cirrus. From the few observations we have, we can confirm that fast updraft in situ cirrus (ridge crest in Muhlbauer et al., 2014) have a lower IWC but higher $N_{\text {ice }}$ than liquid origin cirrus (frontal, subtropical jet stream and anvil cirrus in Muhlbauer et al., 2014).

\section{Summary and conclusions}

The goal of this study is to track cirrus IWC development with temperature by means of model simulations, compare the simulations with observations in the IWC-T parameter space and then assign, to a certain degree, cirrus microphysics to the observations.

To this end, an extensive set of model simulations, covering the broad range of atmospheric conditions for cirrus formation and evolution, is compiled, which we call the Cirrus Guide. Further, cirrus data sets from 17 aircraft campaigns, conducted between 1999 and 2014, spending about $94 \mathrm{~h}$ in cirrus over Europe, Australia, Brazil as well as Southern and Northern America are evaluated.

We found good agreement between observations and simulations, demonstrating that the Cirrus Guide is applicable for the interpretation of observations. A summary of the findings with respect to cirrus microphysics is provided in a sketch of the IWC-T parameter space shown in Fig. 13.

1. Two different types of cirrus are characterized in our study. The first represents the "classical" cirrus (simulated in the Cirrus Guide), where the ice crystals form heterogeneously+homogeneously directly from the gas phase ("in situ origin cirrus", greenish color in Fig. 13). The second type consists of ice crystals formed by het- erogeneous (or sometimes homogeneous) freezing of liquid drops farther below in the atmosphere which are uplifted into the cirrus temperature range ("liquid origin cirrus", blueish color in Fig. 13). The liquid origin cirrus are not included in our simulations, but are identified from the observations. These two cirrus types in general can be distinguished by IWC, where in situ cirrus are preferably thin with lower IWC, while liquid origin cirrus are mostly thick with higher IWC. In addition, the liquid origin cirrus seems to have larger ice crystals than the in situ cirrus. The microphysical properties of the two cirrus types are further investigated by Luebke et al. (2015).

2. Within the in situ cirrus, two classes are also identified. (1) The first are thin cirrus that appear in slow updraft situations (range up to about $0.1 \mathrm{~m} \mathrm{~s}^{-1}$ ). Their IWC is low and they consist of few, large ice crystals. Due to the slow updraft, their microphysical properties are only slightly dependent on the type of ice nucleation (heterogeneous or homogeneous). They appear in low or high pressure frontal systems and thus have a large geographic coverage and a long lifetime. (2) The second in situ cirrus class are thick cirrus forming in fast updrafts triggered by jet streams or atmospheric waves (i.e., leewave cirrus). They have high IWCs and many, small ice crystals. Their formation mechanism is dominated by homogeneous freezing, i.e., they are not sensitive to IN properties. The geographic coverage of fast updraft in situ cirrus is low. In principle they have a short lifetime, unless they do not form continuously in standing waves as, e.g., orographic cirrus downstream of mountains.

3. Analyzing the cirrus over the European and American continents, we found that over Europe in situ and liquid origin cirrus in slow updrafts (warm conveyor belts, high pressure systems) are observed most frequently. Over the American continent, liquid origin cirrus in fast updrafts (mesoscale convective systems, tropical convection) were more abundant in the observations.

To conclusively draw a line from cirrus to the Earth's climate, we suggest here - and will further investigate - that on average the physically and optically thinner in situ slow updraft cirrus cause a warming effect, while only thick fast updraft in situ and particularly thick liquid origin cirrus have the potential to cool.

Acknowledgements. The authors thank the coordinators (listed below) and all teams which were engaged in the field experiments compiled in the study presented here. Progress in the challenging task to understand cirrus clouds and their formation mechanism for most atmospheric conditions was only possible due to the large effort flowing into all the experiments. We also thank Paul Lawson for providing 2D-S data from the MACPEX campaign. Funding is partly provided by the DFG HALO-SPP 
project ACIS (KR 2957/1-1). Campaign coordinators: APETHESEO 1999 (Bruno Carli and Kees Blom), ENVISAT 2002 (Kees Blom), EUPLEX 2003 (Fred Stroh and Hans Schlager), ENVISAT 2003 (Kees Blom), TROCCINOX 2005 (Ulrich Schumann and Hans Schlager), SCOUT-O3 2005 (Cornelius Schiller), AMMA 2006: (Kathy Law and Francesco Cairo), MidCix 2004 (Gerald Mace and Andy Heymsfield), TC-4 2007 (Brian Toon), MACPEX 2011 (Eric Jensen and Gerald Mace), COALESC 2011 (Phil Brown), AIRTOSS 2013 (Manfred Wendisch, Peter Spichtinger and Stephan Borrmann), ML-CIRRUS 2014 (Christiane Voigt, Andreas Minkin and Ulrich Schumann), ACRIDICON 2014 (Manfred Wendisch, Uli Pöschl, Meinrad Andreae and Luiz Machado), ATTREX 2014 (Eric Jensen and Leonhard Pfister). Thanks to the authors of HG2G for inspiring the title.

The article processing charges for this open-access publication were covered by a Research

Centre of the Helmholtz Association.

Edited by: T. Garrett

\section{References}

Archuleta, C. M., DeMott, P. J., and Kreidenweis, S. M.: Ice nucleation by surrogates for atmospheric mineral dust and mineral dust/sulfate particles at cirrus temperatures, Atmos. Chem. Phys., 5, 2617-2634, doi:10.5194/acp-5-2617-2005, 2005.

Baumgardner, D., Jonsson, H., Dawson, W., O'Connor, D., and Newton, R.: The cloud, aerosol and precipitation spectrometer (CAPS): a new instrument for cloud investigations, Atmos. Res., 59-60, 251-264, 2001.

Boucher, O., Randall, D., Artaxo, P., Bretherton, C., Feingold, G., Forster, P., Kerminen, V.-M., Kondo, Y., Liao, H., Lohmann, U., Rasch, P., Satheesh, S., Sherwood, S., Stevens, B., and Zhang, X.: Clouds and Aerosols, in: Climate Change 2013: The Physical Science Basis, Contribution of Working Group I to the Fifth Assessment Report of the Intergovernmental Panel on Climate Change, edited by: Stocker, T. F., Qin, D., Plattner, G.-K., Tignor, M., Allen, S. K., Boschung, J., Nauels, A., Xia, Y., Bex, V., and Midgley, P. M., Cambridge University Press, Cambridge, United Kingdom and New York, NY, USA, 2013.

Buchholz, B., Kühnreich, B., Smit, H. G. J., and Ebert, V.: Validation of an extractive, airborne, compact TDL spectrometer for atmospheric humidity sensing by blind intercomparison, Appl. Phys. B - Lasers O., 110, 249-262, 2013.

Bunz, H., Benz, S., Gensch, I., and Krämer, M.: MAID: a model to simulate UT/LS aerosols and ice clouds, Environ. Res. Lett., 3, 035001, doi:10.1088/1748-9326/3/3/035001, 2008.

Comstock, J. M., Ackerman, T. P., and Mace, G. G.: Ground-based lidar and radar remote sensing of tropical cirrus clouds at Nauru Island: cloud statistics and radiative impacts, J. Geophys. Res., 107, 1-4, 2002.

Cox, S.: Cirrus clouds and climate, J. Atmos. Sci., 28, 1513-1515, 1971.

Cziczo, D., Murphy, D., Hudson, P., and Thomson, D. S.: Single particle measurements of the chemical composition of cir- rus ice residue during CRYSTAL-FACE, J. Geophys. Res., 109, D04201, doi:10.1029/2003JD004032, 2004.

Cziczo, D. J., Froyd, K. D., Hoose, C., Jensen, E. J., Diao, M., Zondlo, M. A., Smith, J. B., Twohy, C. H., and Murphy, D. M.: Clarifying the dominant sources and mechanisms of cirrus cloud formation, Science, 40, 1320-1324, 2013.

DeMott, P. J., Cziczo, D., Prenni, A., Murphy, D., Kreidenweis, S., Thomson, D., Borys, R., and Rogers, D.: Measurements of the concentration and composition of nuclei for cirrus formation, $\mathrm{P}$. Natl. Acad. Sci. USA, 100, 14655-14660, 2003.

Dinh, T., Fueglistaler, S., Durran, D., and Ackerman, T.: Cirrus and water vapour transport in the tropical tropopause layer Part 2: Roles of ice nucleation and sedimentation, cloud dynamics, and moisture conditions, Atmos. Chem. Phys., 14, 1222512236, doi:10.5194/acp-14-12225-2014, 2014.

Dinh, T., Podglajen, A., Hertzog, A., Legras, B., and Plougonven, R.: Effect of gravity wave temperature fluctuations on homogeneous ice nucleation in the tropical tropopause layer, Atmos. Chem. Phys., 16, 35-46, doi:10.5194/acp-16-35-2016, 2016.

Erfani, E. and Mitchell, D. L.: Developing and bounding ice particle mass- and area-dimension expressions for use in atmospheric models and remote sensing, Atmos. Chem. Phys. Discuss., 15, 28517-28573, doi:10.5194/acpd-15-28517-2015, 2015.

Fahey, D. W., Gao, R.-S., Möhler, O., Saathoff, H., Schiller, C., Ebert, V., Krämer, M., Peter, T., Amarouche, N., Avallone, L. M., Bauer, R., Bozóki, Z., Christensen, L. E., Davis, S. M., Durry, G., Dyroff, C., Herman, R. L., Hunsmann, S., Khaykin, S. M., Mackrodt, P., Meyer, J., Smith, J. B., Spelten, N., Troy, R. F., Vömel, H., Wagner, S., and Wienhold, F. G.: The AquaVIT-1 intercomparison of atmospheric water vapor measurement techniques, Atmos. Meas. Tech., 7, 3177-3213, doi:10.5194/amt-7-3177-2014, 2014.

Finger, F., Werner, F., Klingebiel, M., Ehrlich, A., Jäkel, E., Voigt, M., Borrmann, S., Spichtinger, P., and Wendisch, M.: Spectral optical layer properties of cirrus from collocated airborne measurements - a feasibility study, Atmos. Chem. Phys. Discuss., 15, 19045-19077, doi:10.5194/acpd-15-19045-2015, 2015.

Frey, W., Borrmann, S., Kunkel, D., Weigel, R., de Reus, M., Schlager, H., Roiger, A., Voigt, C., Hoor, P., Curtius, J., Krämer, M., Schiller, C., Volk, C. M., Homan, C. D., Fierli, F., Di Donfrancesco, G., Ulanovsky, A., Ravegnani, F., Sitnikov, N. M., Viciani, S., D’Amato, F., Shur, G. N., Belyaev, G. V., Law, K. S., and Cairo, F.: In situ measurements of tropical cloud properties in the West African Monsoon: upper tropospheric ice clouds, Mesoscale Convective System outflow, and subvisual cirrus, Atmos. Chem. Phys., 11, 5569-5590, doi:10.5194/acp-11-55692011, 2011.

Frey, W., Borrmann, S., Fierli, F., Weigel, R., Mitev, V., Matthey, R., Ravegnani, F., Sitnikov, N. M., Ulanovsky, A., and Cairo, F.: Tropical deep convective life cycle: Cb-anvil cloud microphysics from high-altitude aircraft observations, Atmos. Chem. Phys., 14, 13223-13240, doi:10.5194/acp-14-13223-2014, 2014.

Gayet, J.-F., Ovarlez, J., Shcherbakov, V., Ström, M., Schumann, U., Minikin, A., Auriol, F., Petzold, A., and Monier, M.: Cirrus cloud microphysical and optical properties at southern and northern midlatitudes during the INCA experiment, J. Geophys. Res., 109, D20206, doi:10.1029/2004JD004803, 2004.

Gensch, I., Bunz, H., Baumgardner, D., Christensen, L., Fahey, D., Hermann, R., Lawson, P., Popp, P., Smith, J., Webster, C., Wein- 
stock, E., Wilson, J., Peter, T., and Krämer, M.: Supersaturations, microphysics and nitric acid partitioning in a cold cirrus observed during CR-AVE 2006: an observation-modeling intercomparison study, Environ. Res. Lett., 3, 035003, doi:10.1088/17489326/3/3/035003, 2008.

Gettelman, A., Liu, X., Ghan, S. J., Morrison, H., Park, S., Conley, A. J., Klein, S. A., Boyle, J., Mitchell, D. L., and Li, J.-L.F.: Global simulations of ice nucleation and ice supersaturation with an improved cloud scheme in the Community Atmosphere Model, J. Geophys. Res., 115, D18216, doi:10.1029/2009JD013797, 2010.

Heymsfield, A. and Iaquinta, J.: Cirrus crystal terminal velocities, J. Atmos. Sci., 57, 916-938, 2000.

Heymsfield, A., Schmitt, C., and Bansemer, A.: Ice cloud particle size distributions and pressure-dependent terminal velocities from in situ observations at temperatures from $0^{\circ}$ to $286^{\circ} \mathrm{C}$, J. Atmos. Sci., 20, 4123-4154, doi:10.1175/JAS-D-12-0124.1, 2013.

Heymsfield, A. J., Bansemer, A., Field, P. R., Durden, S. L., Stith, J. L., Dye, J. E., Hall, W., and Grainger, C. A.: Observations and parameterizations of particle size distributions in deep tropical cirrus and stratiform precipitating clouds: results from in situ observations in TRMM field campaigns, J. Atmos. Sci., 59, 34573491, 2002a.

Heymsfield, A. J., Lewis, S., Bansemer, A., Iaquinta, J., Miloshevich, L. M., Kajikawa, M., Twohy, C., and Poellot, M. R.: A general approach for deriving the properties of cirrus and stratiform ice cloud particles, J. Atmos. Sci., 59, 3-29, 2002 b.

Hoose, C. and Möhler, O.: Heterogeneous ice nucleation on atmospheric aerosols: a review of results from laboratory experiments, Atmos. Chem. Phys., 12, 9817-9854, doi:10.5194/acp-12-98172012, 2012.

Jackson, R. C., McFarquhar, G. M., Fridland, A. M., and Atlas, R.: The dependence of cirrus gamma size distributions expressed as volumes in $N_{0}-\lambda-\mu$ phase space and bulk cloud properties on environmental conditions: Results from the Small Ice Particles in Cirrus Experiment (SPARTICUS), J. Geophys. Res. Atmos., 120, 10351-10377, doi:10.1002/2015JD023492, 2015.

Jensen, E., Diskin, G., Lawson, Lance, P., S., Bui, T., Hlavka, D., McGill, M., Pfister, L., Toon, O., and Gao, R.: Ice nucleation and dehydration in the Tropical Tropopause Layer, P. Natl. Acad. Sci. USA, 110, 2041-2046, doi:10.1073/pnas.1217104110, 2013a.

Jensen, E., Lawson, P., Bergman, J. W., Pfister, L., Bui, T. P., and Schmitt, C. G.: Physical processes controlling ice concentrations in synoptically forced, midlatitude cirrus, J. Geophys. Res., 118, 5348-5360, doi:10.1002/jgrd.50421, 2013b.

Jones, H. M., Haywood, J., Marenco, F., O’Sullivan, D., Meyer, J., Thorpe, R., Gallagher, M. W., Krämer, M., Bower, K. N., Rädel, G., Rap, A., Woolley, A., Forster, P., and Coe, H.: A methodology for in-situ and remote sensing of microphysical and radiative properties of contrails as they evolve into cirrus, Atmos. Chem. Phys., 12, 8157-8175, doi:10.5194/acp-12-8157-2012, 2012.

Kärcher, B. and Lohmann, U.: A parameterization of cirrus cloud formation: homogeneous freezing of supercooled aerosols, J. Geophys. Res., 107, 4010, doi:10.1029/2001JD000470, 2002.

Kärcher, B. and Lohmann, U.: A parameterization of cirrus cloud formation: heterogeneous freezing, J. Geophys. Res., 108, 4402, doi:10.1029/2002JD003220, 2003.
Kärcher, B., Hendricks, J., and Lohmann, U.: Physically based parameterization of cirrus cloud formation for use in global atmospheric models, J. Geophys. Res., 111, D01205, doi:10.1029/2005JD006219, 2006.

Kienast-Sjögren, E., Miltenberger, A. K., Luo, B. P., and Peter, T.: Sensitivities of Lagrangian modelling of mid-latitude cirrus clouds to trajectory data quality, Atmos. Chem. Phys., 15, 74297447, doi:10.5194/acp-15-7429-2015, 2015.

Koop, T., Luo, B., Tsias, A., and Peter, T.: Water activity as the determinant for homogeneous ice nucleation in aqueous solutions, Nature, 406, 611-614, 2000.

Korolev, A., Emery, E., Strapp, J., Cober, S., Isaac, G., Wasey, M., and Marcotte, D.: Small ice particles in tropospheric clouds: fact or artifact? Airborne Icing Instrumentation Evaluation Experiment, B. Am. Meteorol. Soc., 92, 967-973, doi:10.1175/2010BAMS3141.1, 2011.

Korolev, A., Emery, E., Strapp, J., Cober, S., and Isaac, G.: Quantification of the effects of shattering on airborne ice particle measurements, J. Atmos. Ocean. Tech., 92, 2527-2553, doi:10.1175/JTECH-D-13-00115.1, 2013.

Krämer, M., Schiller, C., Afchine, A., Bauer, R., Gensch, I., Mangold, A., Schlicht, S., Spelten, N., Sitnikov, N., Borrmann, S., de Reus, M., and Spichtinger, P.: Ice supersaturations and cirrus cloud crystal numbers, Atmos. Chem. Phys., 9, 3505-3522, doi:10.5194/acp-9-3505-2009, 2009.

Krämer, M., Twohy, C., Hermann, M., Afchine, A., Dhaniyala, S., and Korolev, A.: Aerosol and cloud particle sampling, in: Airborne Measurements for Environmental Research: Methods and Instruments, edited by: Wendisch, M. and Brenguier, J.-L., Wiley-VCH Verlag GmbH \&Co. KGaA, Weinheim, Germany, 303-341, doi:10.1002/9783527653218.ch6, 2013.

Lawson, R., O'Connor, D., Zmarzly, P., Weaver, K., Baker, B., Mo, Q., and Jonsson, H.: The 2D-S (Stereo) probe: design and preliminary tests of a new airborne, high-speed, high-resolution particle imaging probe, J. Atmos. Ocean. Tech., 23, 1462-1477, 2006.

Luebke, A. E., Avallone, L. M., Schiller, C., Meyer, J., Rolf, C., and Krämer, M.: Ice water content of Arctic, midlatitude, and tropical cirrus - Part 2: Extension of the database and new statistical analysis, Atmos. Chem. Phys., 13, 6447-6459, doi:10.5194/acp13-6447-2013, 2013.

Luebke, A. E., Afchine, A., Costa, A., Meyer, J., Rolf, C., Spelten, N., Avallone, L. M., Baumgardner, D., and Krämer, M.: The origin of midlatitude ice clouds and the resulting influence on their microphysical properties, Atmos. Chem. Phys. Discuss., 15, 34243-34281, doi:10.5194/acpd-15-34243-2015, 2015.

May, R.: Open-path, near-infrared tunable diode laser spectrometer for atmospheric measurements of $\mathrm{H}_{2} \mathrm{O}$, J. Geophys. Res., 103, 19161-19172, doi:10.1029/98jd01678, 1998.

McFarquhar, G., Heymsfield, A., Spinhirne, J., and Hart, B.: Thin and subvisual tropopause tropical cirrus: observations and radiative impact, J. Atmos. Sci., 57, 1841-1853, 2000.

McFarquhar, G., Schmid, B., Korolev, A., Ogren, J., Russell, P., Tomlinson, J., Turner, D., and Wiscombe, W.: Airborne instrumentation needs for climate and atmospheric research, B. Am. Meteorol. Soc., 92, 1193-1196, doi:10.1175/2011BAMS3180.1, 2011.

Meyer, J.: Ice Crystal Measurements with the New Particle Spectrometer NIXE-CAPS, Schriften des Forschungszentrums Jülich, 
Reihe Energie und Umwelt/Energy and Environment, vol. 160, ISBN:9783893368402, Forschungszentrum Jülich, Jülich, Germany, 2012.

Meyer, J., Rolf, C., Schiller, C., Rohs, S., Spelten, N., Afchine, A., Zöger, M., Sitnikov, N., Thornberry, T. D., Rollins, A. W., Bozóki, Z., Tátrai, D., Ebert, V., Kühnreich, B., Mackrodt, P., Möhler, O., Saathoff, H., Rosenlof, K. H., and Krämer, M.: Two decades of water vapor measurements with the FISH fluorescence hygrometer: a review, Atmos. Chem. Phys., 15, 85218538, doi:10.5194/acp-15-8521-2015, 2015.

Mitchell, D. L., D'Entrmont, R. P., and Lawson, R. P.: Inferring cirrus size distributions through satellite remote sensing and microphysical databases, J. Atmos. Sci., 67, 1106-1125, doi:10.1175/2009JAS3150.1, 2010.

Möhler, O., Field, P. R., Connolly, P., Benz, S., Saathoff, H., Schnaiter, M., Wagner, R., Cotton, R., Krämer, M., Mangold, A., and Heymsfield, A. J.: Efficiency of the deposition mode ice nucleation on mineral dust particles, Atmos. Chem. Phys., 6, 30073021, doi:10.5194/acp-6-3007-2006, 2006.

Muhlbauer, A., Ackerman, T., Comstock, J., Diskin, G., Evans, S., Lawson, R., and Marchand, R.: Impact of large-scale dynamics on the microphysical properties of midlatitude cirrus, J. Geophys. Res.-Atmos., 119, 3976-3996, doi:10.1002/2013JD020035, 2014.

Murphy, D. and Koop, T.: Review of the vapour pressure of ice and supercooled water for atmospheric applications, Q. J. Roy. Meteor. Soc., 131, 1539-1565, 2005.

Peter, T., Marcolli, C., Spichtinger, P., Corti, T., Baker, M., and Koop, T.: When dry air is too humid, Science, 314, 1399-1401, 2006.

Rolf, C., Krämer, M., Schiller, C., Hildebrandt, M., and Riese, M.: Lidar observation and model simulation of a volcanicash-induced cirrus cloud during the Eyjafjallajökull eruption, Atmos. Chem. Phys., 12, 10281-10294, doi:10.5194/acp-1210281-2012, 2012.

Rollins, A. W., Thornberry, T. D., Gao, R. S., Smith, J. B., Sayres, D. S., Sargent, M. R., Schiller, C., Krämer, M., Spelten, N., Hurst, D. F., Jordan, A. F., Hall, E. G., Vömel, H., Diskin, G. S., Podolske, J. R., Christensen, L. E., Rosenlof, K. H., Jensen, E. J., and Fahey, D. W.: Evaluation of UT/LS hygrometer accuracy by intercomparison during the NASA MACPEX mission, J. Geophys. Res.-Atmos., 119, 1915-1935, doi:10.1002/2013JD020817, 2014.

Sassen, K.: Cirrus Clouds: A modern perspective, in: Cirrus, edited by: Lynch, D., Sassen, K., Starr, D., and Stephens, G., Oxford University Press, Inc., New York, 11-40, ISBN:0-19-513072-3, 2002.
Sassen, K. and Benson, S.: A midlatitude cirrus cloud climatology from the facility for atmospheric remote sensing. Part II: Microphysical properties derived from lidar depolarization, J. Atmos. Sci., 58, 2103-2112, doi:10.1175/15200469(2001)058<2103:AMCCCF>2.0.CO;2, 2001.

Sassen, K., Wang, Z., and Liu, D.: Global distribution of cirrus clouds from CloudSat/Cloud-Aerosol Lidar and Infrared Pathfinder Satellite Observations (CALIPSO) measurements, J. Geophys. Res., 113, D00A12, doi:10.1029/2008JD009972, 2008.

Schiller, C., Krämer, M., Afchine, A., Spelten, N., and Sitnikov, N.: Ice water content in Arctic, midlatitude and tropical cirrus, J. Geophys. Res., 113, D24208, doi:10.1029/2008JD010342, 2008.

Spichtinger, P. and Gierens, K. M.: Modelling of cirrus clouds Part 1a: Model description and validation, Atmos. Chem. Phys., 9, 685-706, doi:10.5194/acp-9-685-2009, 2009.

Spichtinger, P. and Krämer, M.: Tropical tropopause ice clouds: a dynamic approach to the mystery of low crystal numbers, Atmos. Chem. Phys., 13, 9801-9818, doi:10.5194/acp-13-98012013, 2013.

Voigt, C. E. A.: ML-CIRRUS - a field experiment on natural and aviation induced cirrus with the new German research aircraft HALO, B. Am. Meteorol. Soc., submitted, 2016.

Wendisch, M., Pöschl, U., Andreae, M., Machado, L., Albrecht, R., Schlager, H., Rosenfeld, D., Martin, S., Abdelmonem, A., Afchine, A., Araujo, A., Artaxo, P., Aufmhoff, H., Barbosa, H., Borrmann, S., Braga, R., Buchholz, B., Cecchini, M., Costa, A., Curtius, J., Dollner, M., Dorf, M., Dreiling, V., Ebert, V., Ehrlich, A., Ewald, F., Fisch, G., Fix, A., Frank, F., Fütterer, D., Heckl, C., Heidelberg, F., Hüneke, T., Jäkel, E., Jaervinen, E., Jurkat, T., Kanter, S., Kästner, U., Kenntner, M., Kesselmeier, J., Klimach, T., Knecht, M., Kohl, R., Kölling, T., Krämer, M., Krüger, M., Krisna, T., Lavric, J., Longo, K., Mahnke, C., Manzi, A., Mayer, B., Mertes, S., Minikin, A., Molleker, S., Muench, S., Nillius, B., Pfeilsticker, K., Pöhlker, C., Roiger, A., Rose, D., Rosenow, D., Sauer, D., Schnaiter, M., Schneider, J., Schulz, C., de Souza, R., Spanu, A., Stock, P., Vila, D., Voigt, C., Walser, A., Walter, D., Weigel, R., Weinzierl, B., Werner, F., Yamasoe, M., Ziereis, H., Zinner, T., and Zöger, M.: The ACRIDICO N-CHUVA campaign: Studying tropical deep convective clouds and precipitation ov er Amazonia using the new German research aircraft HALO, B. Am. Meteorol. Soc., doi:10.1175/BAMS-D-14-00255.1, in press, 2016. 